\title{
Targeted Interleukin-10 Nanotherapeutics Developed with a Microfluidic Chip Enhance Resolution of Inflammation in Advanced Atherosclerosis
}

\author{
Nazila Kamaly ${ }^{\dagger}, \nabla$, Gabrielle Fredman ${ }^{\ddagger, \nabla}$, Jhalique Jane R. Fojas ${ }^{\dagger}$, Manikandan \\ Subramanian $\ddagger$, Won Choi II ${ }^{\dagger} \S$, Katherine Zepeda ${ }^{\dagger}$, Cristian Vilos ${ }^{\dagger}, \|$, Mikyung Yu ${ }^{\dagger}$, Suresh \\ Gadde $^{\dagger}$, Jun $\mathrm{Wu}^{\dagger}$, Jaclyn Milton ${ }^{\dagger}$, Renata Carvalho Leitao ${ }^{\dagger}$, Livia Rosa Fernandes ${ }^{\dagger}$, Moaraj \\ Hasan $^{\dagger}$, Huayi Gao ${ }^{\dagger}$, Vance Nguyen ${ }^{\dagger}$, Jordan Harris ${ }^{\dagger}$, Ira Tabas ${ }^{\ddagger},{ }^{\star}$, and Omid C. \\ Farokhzad ${ }^{\dagger, \perp,{ }^{*}}$ \\ †Laboratory of Nanomedicine and Biomaterials, Harvard Medical School, Department of \\ Anesthesiology, Brigham and Women's Hospital, Boston, Massachusetts 02115, United States \\ ‡Departments of Medicine, Pathology and Cell Biology, and Physiology and Cellular Biophysics, \\ Columbia University, New York, New York 10032, United States \\ $\S$ Center for Convergence Bioceramic Materials, Convergence R\&D Division, Korea Institute of \\ Ceramic Engineering and Technology, 101, Soho-ro, Jinj-si, Gyeongsangnam-do 52851, Republic \\ of Korea
}

"Facultad de Medicina, Center for Integrative and Innovative Science, Universidad Andres Bello, Echaurren 183, Santiago 8370071, Chile

${ }^{\perp}$ King Abdulaziz University, Jeddah 21589, Saudi Arabia

\section{Abstract}

Inflammation is an essential protective biological response involving a coordinated cascade of signals between cytokines and immune signaling molecules that facilitate return to tissue homeostasis after acute injury or infection. However, inflammation is not effectively resolved in chronic inflammatory diseases such as atherosclerosis and can lead to tissue damage and exacerbation of the underlying condition. Therapeutics that dampen inflammation and enhance resolution are currently of considerable interest, in particular those that temper inflammation with minimal host collateral damage. Here we present the development and efficacy investigations of

\footnotetext{
*Corresponding Authors: ofarokhzad@bwh.harvard.edu. iat1@columbia.edu.

$\nabla$ Author Contributions

These authors contributed equally.

Author Contributions

N.K., G.F., I.T., and O.C.F. designed research; N.K, G.F., J.J.F., M.S., W.I.C., K.Z., C.V., M.Y., S.G., J.W., J.M., R.L., L.R., M.H., H.G., V.N., J.H. performed research; N.K., G.F., O.C.F., and I.T. analyzed data; N.K., G.F., I.T., and O.C.F. wrote the paper.

Supporting Information

The Supporting Information is available free of charge on the ACS Publications website at DOI: 10.1021/acsnano.6b01114. Materials and further figures (PDF)

The authors declare the following competing financial interest(s): O.C.F. has financial interests in BIND Therapeutics, Selecta Biosciences, Tarveda Therapeutics and Placon Therapeutics, which are developing nanoparticle technologies for medical applications. These companies did not support the aforementioned research and currently have no rights to any technology or intellectual property developed as part of this research. All other authors declare no conflicts.
} 
controlled-release polymeric nanoparticles incorporating the anti-inflammatory cytokine interleukin 10 (IL-10) for targeted delivery to atherosclerotic plaques. Nanoparticles were nanoengineered via self-assembly of biodegradable polyester polymers by nanoprecipitation using a rapid micromixer chip capable of producing nanoparticles with retained IL-10 bioactivity postexposure to organic solvent. A systematic combinatorial approach was taken to screen nanoparticles, resulting in an optimal bioactive formulation from in vitro and ex vivo studies. The most potent nanoparticle termed Col-IV IL-10 NP22 significantly tempered acute inflammation in a self-limited peritonitis model and was shown to be more potent than native IL-10. Furthermore, the Col-IV IL-10 nanoparticles prevented vulnerable plaque formation by increasing fibrous cap thickness and decreasing necrotic cores in advanced lesions of high fat-fed $\mathrm{LDLr}^{-/-}$mice. These results demonstrate the efficacy and pro-resolving potential of this engineered nanoparticle for controlled delivery of the potent IL-10 cytokine for the treatment of atherosclerosis.

\section{Graphical Abstract}

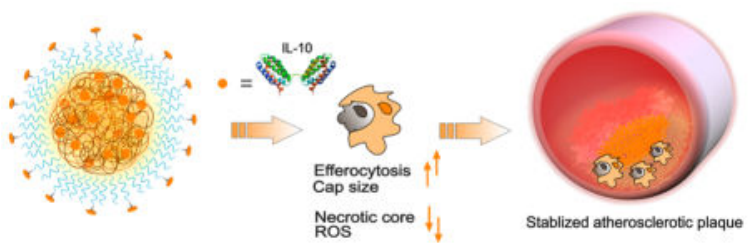

\section{Keywords}

nanomedicine; IL-10; polymeric nanoparticles; inflammation; atherosclerosis; microfluidics

Following the onset of inflammation, the resolution phase quells inflammation and restores tissue homeostasis. ${ }^{1}$ However, for chronic diseases in which the pathologic stimulus is continuously present at the site of inflammation, the resolution phase is defective, leading to a cycle of tissue injury and progressive inflammation. ${ }^{2}$ Recent evidence has shown defective resolution of inflammation to be a major pathogenic factor in the clinical progression of atherosclerosis. ${ }^{2-5} \mathrm{~A}$ key underlying cause of inflammation in atherosclerosis is the persistent pro-inflammatory stimulus arising from increasing levels of subendothelial apoBlipoproteins during plaque progression. ${ }^{6}$ Defective resolution in clinically high-risk advanced human plaques manifests as fibrous cap thinning, high oxidative stress, defective clearance of dead cells (efferocytosis), and tissue-damaging necrosis. ${ }^{7,8}$ Currently atherosclerosis treatment mainly involves the use of small-molecule drugs such as statins that lower the levels of low-density lipoprotein (LDL), and more recently antibody treatments against the proprotein convertase subtilisin/kexin type 9 (PCSK9) enzyme have been developed to achieve the same effect. ${ }^{9}$ However, cardiovascular disease is still the leading cause of death worldwide, and new targeted- anti-inflammatory therapies that resolve inflammation via endogenous counter-regulatory processes have the potential to be beneficial and complementary to LDL-lowering therapies. ${ }^{10,11}$

In the innate setting, resolution is mediated by proresolving lipids (e.g., lipoxins, resolvins, protectins, and maresins) and protein mediators (e.g., interleukin-10 (IL-10), transforming growth factor- $\beta$ (TGF $\beta$ ), and annexin A1) that can block inflammatory cell accumulation 
and promote their egress, clear pathogens, cellular debris, and inflammatory cytokines, stimulate efferocytosis, and repair damaged tissue. ${ }^{12,13}$ Furthermore, these endogenous biological mediators of inflammation have great potential for tempering inflammation and promoting tissue repair without compromising host defense. ${ }^{14}$ Therefore, enhancing the effective natural resolution of inflammation within the local plaque environment is an attractive alternative therapy for cardiovascular disease and can be achieved using nanotechnology strategies. ${ }^{15}$

In our previous work we developed targeted polymeric nanoparticles (NPs) that tempered maladaptive characteristics of advanced atherosclerotic lesions via the delivery of the proresolving annexin A1 biomimetic peptide Ac2-26. ${ }^{16,17}$ This peptide is protective in an advanced atherosclerotic setting by activating the $N$-formyl peptide receptor 2 (FPR2/ALX), the receptor for endogenous annexin A1. ${ }^{18}$ Following on from these studies and to investigate biological treatment options for atherosclerosis therapy, here we extend similar nanoengineering concepts to the delivery of the anti-inflammatory cytokine IL-10 to atherosclerotic plaques (Figure 1). The choice of a potent proresolving mediator such as IL-10 and its protected, targeted, and specific nanodelivery to the site of atherosclerotic plaques has the potential to terminate leukocyte recruitment, counter-regulate proinflammatory mediators, stimulate efferocytosis, dampen oxidative stress, and promote fibrous cap formation. ${ }^{2}$

IL-10, a dimer that interacts with a heterodimeric receptor complex consisting of IL-10R $a$ and IL-10R $\beta$ subunits, is a soluble cytokine produced by various inflammatory cells including macrophages and regulatory $\mathrm{T}$ cells and plays a major role in limiting host immune response to pathogens, preventing damage to the host, and maintaining tissue homeostasis. ${ }^{19,20} \mathrm{IL}-10$ levels in patients with vulnerable plaques have been found to be significantly lower than healthy controls, and this cytokine has been shown to suppress atherosclerosis. ${ }^{20-22}$ Interestingly, one study reported that elevated baseline IL-10 levels in patients diagnosed with acute coronary syndrome were a strong and independent predictor of long-term adverse cardiovascular effects. ${ }^{23}$ Further studies are needed to reproduce this observation and to explain the mechanism of the association, e.g., whether high IL-10 represents a compensatory response to a heightened inflammatory state. ${ }^{24,25}$ Since IL-10 has a short systemic half-life, ${ }^{26}$ and long-term systemic IL-10 therapy could have substantial adverse effects, ${ }^{27,28}$ targeted and controlled-release, NP-mediated delivery of IL-10 to sites of inflammation could prove effective and improve the pharmaceutical and pharmacological properties of this potent cytokine.

IL-10 has been used as a targeting moiety conjugated to the surface of liposomes and protamine-oligonucleotide NPs, which were shown to effectively detect atherosclerotic plaques in apolipoprotein E (ApoE)-deficient mice. ${ }^{29,30}$ However, due to the short systemic half-life of IL-10 for effective therapeutic purposes, encapsulation and therefore protection of this potent protein in nanocarrier systems with controlled release properties may be an optimal approach. For this reason, we chose to utilize biodegradable controlled-release polyesters in the form of poly(D-lactic acid) (PLA) and poly lactic-co-glycolic acid (PLGA) polymers to form protective NPs for targeted IL-10 delivery. Polymeric materials have emerged as a major class of controlled-release systems, as their unique physicochemical, 
synthetic, biocompatibility, and degradation properties can be readily manipulated using well-established techniques. ${ }^{31,32}$ A further major advantage of polymeric NPs is the fact that they can release payloads over time in a targeted and controlled manner, facilitating a lower dosing frequency, which is ideal for potent therapeutic proteins. ${ }^{31,33,34}$

The successful delivery of inflammation-resolving mediators to atherosclerotic plaques also requires an effective targeting strategy. The accumulation of nanomedicines in tumors has resulted from intrinsic tumor properties such as dysfunctional endothelia, leaky vessels, and microvasculature hyper-permeability, ${ }^{2}$ which together facilitate NP accumulation through the enhanced permeability and retention (EPR) effect. ${ }^{35}$ Analogous to tumors, atherosclerotic plaques also present dysfunctional endothelia and a permeable vasa vasorum, which can facilitate the accumulation of NPs within plaques. ${ }^{36}$ Through phage display investigations, we previously identified peptide sequences that have affinity toward collagen IV (Col IV). ${ }^{37}$ This protein is overexposed at sites of vascular breach, and since more than $50 \%$ of the lesional basement is comprised of $\mathrm{Col} \mathrm{IV},{ }^{38}$ we chose to utilize this targeting strategy to anchor IL-10 loaded NPs within atherosclerotic plaques in mice. ${ }^{39}$

Using on-chip nanoprecipitation-induced self-assembly of diblock polymers to form an optimized targeted polymeric NP containing Col IV IL-10 NP22, we demonstrate that these NPs have anti-inflammatory effects on macrophages in vitro and ex vivo, in addition to the capability of stabilizing vulnerable plaques by reducing cap thinning and necrotic core buildup in vivo. These results constitute the first targeted controlled-release polymeric NP aided delivery of IL-10 to atherosclerotic plaques and demonstrate a new avenue for combating cardiovascular disease.

\section{RESULTS AND DISCUSSION}

To effectively deliver IL-10 to atherosclerotic plaques, the key NP design requirements are long-circulating NPs to facilitate plaque accumulation, small size to facilitate permeation of the endothelium, molecular targeting to enhance NP retention within plaques, sufficient loading and entrapment of IL-10, and finally, retention of protein bioactivity post-release. Therefore, to identify an optimal polymeric NP composition that yields the greatest IL-10 bioactivity post-encapsulation, we investigated a combinatorial library of NPs made up of clinically validated building-block biomaterials. The design of the NPs using this library incorporated the blending of two core polymers, with the first set of core polymers consisting of either PDLA-COOH, PLGA-NH $\mathrm{N}_{2}$, or $\mathrm{NH}_{2}-$ PLGA-NH 2 (with charged terminal moieties for more effective electrostatic interactions with IL-10), and the second set of core polymers consisting of polyethylene glycol (PEG) diblock polymers (for NP stability, immune shielding, and enhanced circulation); PLGA(75:25)-PEG-OMe, PLGA(50:50)-PEG-OMe, and PDLA-PEG-OMe (Supporting Information Figure S1). In addition to these polymers, D-(+)-glucosamine was mixed with recombinant mouse IL-10 to stabilize the surface of this sensitive protein prior to polymeric entrapment and also as a cryoprotectant for low-temperature storage.

The diblock polymers used in this study were synthesized according to previously published methods using 1-ethyl-3-(3-(dimethylamino)propyl)carbodiimide hydrochloride (EDC) and 
$N$-hydroxysuccinimide (NHS) activation reactions. ${ }^{16}$ To impart a targeting capability to the NPs, a small percentage ( $5 \mathrm{wt} / \mathrm{wt} \%$ of total polymer mass) of the targeting polymer (PLGAPEG-Col IV, which we have previously synthesized and tested) ${ }^{16}$ was also used in each NP to create 12 different NP formulations (termed Col-IV IL-10 NPs). Having synthesized the required polymers, the NPs were fabricated via nanoprecipitation using a glass microfluidic rapid-chip mixer capable of efficient mixing of three streams of solution (using a DMF solvent phase containing the polymer blends) and nonsolvent water phase containing IL-10 and D-(+)-glucosamine (flow rates: $0.1 \mathrm{~mL} / \mathrm{min}$ for IL-10 solution and $0.05 \mathrm{~mL} / \mathrm{min}$ for polymer solutions), leading to the self-assembly of the NPs in the central channel with no fouling (Figures S2 and S3). The utilization of diblock hydrophobic-PEGylated polymers in nanoprecipitation yields NPs that consist of a hydrophobic core containing the entrapped therapeutics, surrounded by a hydrophilic PEG shell for steric stabilization and prolonged systemic circulation (Figure 1a). ${ }^{40}$ The use of a glass microfluidic rapid-chip mixer allows for a high-throughput synthesis of a large number of NPs, and the lamination of the streams reduces diffusion distances, improving the mixing of the aqueous and organic-solvent phases, which is not only necessary for the process of nanoprecipitation but also is optimal for minimal exposure of the IL-10 protein to solvent. In this manner IL-10 NPs could be produced in a matter of minutes, making the combinatorial production of NPs fast and highly reproducible. The NP self-assembly process is driven by nanoprecipitation, which leads to the instantaneous formation of NPs. ${ }^{40}$ This process is governed by the principles of the Marangoni effect, which describes the behavior of interfacial interactions between liquid phases. ${ }^{41}$ Additionally, on-chip nanoprecipitation is a facile method that is amenable to scale-up, producing stable and homogeneous polymeric NP populations. ${ }^{42,43}$

Following on-chip synthesis, Col-IV IL-10 NPs were purified by repeat centrifugation and washing steps and characterized for their physicochemical properties. The specific read-out parameters that were assessed were hydrodynamic NP size, measured using dynamic-light scattering (DLS), and actual NP size measured using transmission-electron microscopy (TEM) (Figure S4a-b). Further parameters measured were NP surface charge/ electrophoretic mobility (Figure S4a), and the total percentage of IL-10 loading and encapsulation for each NP (Figure S5). The hydrodynamic NP sizes ranged between 76.23 $\pm 1.1 \mathrm{~nm}$ and $212.66 \pm 9.5 \mathrm{~nm}$ (Figure S4a) with the average size being $\sim 120 \mathrm{~nm}$ (hydrodynamic). Low-temperature storage is important for preserving IL-10 activity. In order to observe the morphology of the NPs after storage at $-80{ }^{\circ} \mathrm{C}$ for 7 days, the NPs were stained and visualized by TEM (Figure S4b). The NPs were found to be intact and spherical, as observed and measured by TEM, and ranged in size between $44.4 \pm 7.56 \mathrm{~nm}$ and 145.89 $\pm 10.26 \mathrm{~nm}$, confirming their robustness post-low-temperature storage and thawing. Next, the amount of IL-10 incorporated into the NPs was measured using ELISA, and encapsulation efficiency (EE) measurements were found to be within the range $65.57 \%$ (NP8) to $98.19 \%$ (NP22) (Figure S5a). The loading of IL-10 (wt/wt \% of total polymer mass) was also measured and found to be within the range $1.75 \%$ (NP8) to $2.62 \%$ (NP22) (Figure S5b). IL-10 was used at a $4 \%$ nominal loading of total polymer weight, where loading is defined as the \% mass fraction of total protein in the polymeric NPs, and EE is the $\%$ fraction of initial protein that is encapsulated by the NPs. Since IL-10 is highly potent, 
low therapeutic doses (pg-ng/mL) in vivo are sufficient for bioaction, the loading and encapsulation of IL-10 was therefore deemed to be sufficient.

IL-10 activates JAK1 and Tyk2, leading to STAT3 and SOCS3 activation, which stimulates anti-inflammatory mechanisms of IL-10 in macrophages and other immune cells, ${ }^{44,45}$ therefore, the bioactivity of Col-IV IL-10 NPs was assessed using Western blot post-storage ( 7 days at $-80{ }^{\circ} \mathrm{C}$ ) and one thawing cycle. All 24 NPs were separately incubated with RAW 264.7 macrophage cells, and phosphorylated STAT3 (p-STAT3 at Tyr705; which is a marker of STAT3 activation) was measured, with free recombinant IL-10 used as a positive control and $\beta$-actin as the reference protein (Figure S6a). A strong signal was observed for the IL-10 positive control (+IL-10) sample, indicating successful activation of STAT3, which was not observed in the absence of IL-10 (-IL-10). Variable signaling intensities were observed throughout the $24 \mathrm{NPs}$, and following quantitation of the mean p-STAT3 signal from the Western blots, the top signal-inducing formulations were found to be in the order: NP22 > NP4 > NP20 > NP8 > NP14 > NP6 > NP7 > NP1 > NP2 > NP21 > NP18 > NP11 (Figure $\mathrm{S} 6 \mathrm{~b})$. NP22 had both the highest signaling intensity and the highest loading amount of IL-10. In general, the formulations that incorporated D-(+)-glucosamine (the even-numbered NPs) had positive signal intensities, indicating that this additive could help protect IL-10 from the organic solvent as well as freeze-thaw stress. The low signal intensities of the remaining NPs may be attributed to unfavorable interactions between the protein and polymers upon thawing and requires further investigation.

To further analyze the bioactivity of the NPs, we determined their ability to suppress intracellular reactive oxygen species (ROS) generated from lipopolysaccharide (LPS)stimulated RAW 264.7 macrophage cells. The macrophages were primed for $24 \mathrm{~h}$ with 100 $\mathrm{ng} / \mathrm{mL}$ LPS and then incubated for an additional $24 \mathrm{~h}$ with Col-IV IL-10 NPs, IL-10 (50 ng/ $\mathrm{mL}$ ), or controls. The IL-10 NPs were able to reduce overall ROS by $37.53-62.20 \%$ and were $\sim 20-30 \%$ more effective than free IL-10 (Figure S7). Since the various NPs reduced ROS to a similar extent, the p-STAT3 Western blot results (shown above) were used as a guide to further determine the optimal formulations. Accordingly, the 12 NPs that produced the highest p-STAT3 signal were compared for p-STAT3 Western blot signal as a function of hydrodynamic size, TEM size, surface charge, \% EE, and \% loading (Figure 2). Based on these data, the top 6 NPs were chosen for IL-10 release kinetics investigation (NP22, NP4, NP20, NP8, NP14, and NP6). The release profiles of IL-10 from these NPs were investigated by incubating them at $37^{\circ} \mathrm{C}$ and collecting and measuring the released protein at various intervals for up to 6 days using an IL-10 ELISA assay. All 6 NPs showed controlled-release profiles for IL-10, with release kinetics decreasing in the order NP22 > NP20 > NP4 > NP6 > NP14 > NP8 (Figure 3a). The fastest release was observed for NP22, which after 6 days reached $85.25 \%$ of the total entrapped IL-10.

The release profile of the NPs follows a biphasic profile (Figure 3a): Following an initial burst release, there is a slow-release phase governed by slow protein diffusion through the polymer matrix or through existing pores, with eventual polymer hydrolysis and degradation over longer time-frames. ${ }^{46}$ The initial burst-release effect is attributed to the rapid release of surface-bound protein molecules; the second phase (steady controlled release) is related to 
diffusion and hydrolysis. ${ }^{46}$ The slow second phase or lag-phase appearance of the release profiles could suggest a densely packed polymer system with lower porosity. ${ }^{46,47}$

In order to determine whether the 6 Col-IV IL-10 NPs selected for release kinetic measurements can inhibit proinflammatory cytokine production induced in macrophages, the relative mRNA expression level of the proinflammatory cytokine TNF- $a$ (Tnfa) was measured in RAW 264.7 macrophages treated with LPS and then the NPs or free IL-10 control. As expected, LPS treatment led to the induction of Tnfa (Figure 3b), and NP22 showed the greatest degree of suppression, confirming that the released IL-10 from this formulation retains its bioactivity. Furthermore, as predicted, the Tnfa-suppressing ability of the six NPs mirrors the IL-10 release rate from these NPs, confirming that the NPs with the fastest release have the greatest anti-inflammatory effect. In summary, our in vitro Western blot, ROS, and Tnfa experiments confirmed that the IL-10 released from NPs is bioactive. Furthermore, confocal microscopy studies demonstrated a reduction in TNF- $a$ signal in LPS-treated RAW macrophages (Figure S8).

Previous studies have shown that oxidative stress (OS) plays a destructive role in atherosclerosis and that quelling OS can lead to improvements in this disease. ${ }^{48}$ In addition to NADPH oxidase, OS is generated by lesional macrophage mitochondria (mitoOS), and we recently demonstrated that mitoOS in plaque lesional macrophages is marked by the presence of non-nuclear 8-oxo- $2^{\prime}$ deoxyguanosine (8-OHdG) ${ }^{49}$ Therefore, in order to test whether Col-IV IL-10 NPs can quell mitoOS in LPS-activated macrophages, we took the top three NPs in terms of anti-inflammatory bioactivity (NP22, NP20, and NP4) and investigated this effect on bone marrow-derived macrophages. These macrophages were then incubated with 7-ketocholesterol $(7 \mathrm{KC})$ to induce mitoOS ${ }^{49}$ Following incubation with the NPs, the mitoOS was measured using the mitochondria-targeted superoxide detection probe MitoSox. ${ }^{49}$ The data show that all three NPs were similar to free-IL-10 in their ability to significantly lower MitoOS (Figure 4a).

One important hallmark of vulnerable atherosclerotic plaques is a necrotic core, which can grow and rupture over time due, in part, to lesional cell apoptosis coupled with defective phagocytic clearance, or efferocytosis of the apoptotic cells. ${ }^{50,51}$ To ascertain the efferocytosis-promoting capability of the top three Col-IV IL-10 NPs, bone marrow-derived macrophages were treated with IL-10 or Col-IV IL-10 NPs (IL-10 dose: $10 \mathrm{ng} / \mathrm{mL}$ ) for $12 \mathrm{~h}$, after which fluorescently labeled apoptotic Jurkat cells were added at an apoptotic cell: macrophage ratio of 5:1 and cultured for $1 \mathrm{~h}$. The uptake of apoptotic cells by the macrophages was then analyzed by fluorescent microscopy. The data show that all NPs significantly enhanced efferocytosis in a manner similar to free IL-10 (Figure 4b).

The pro-inflammatory cytokine IL- $1 \beta$ has been linked to atherosclerosis progression. ${ }^{52}$ For this reason we sought to investigate the potential of NP22, identified as the optimal Col-IV IL-10 NP from our in vitro and ex vivo studies, for its ability to reduce IL- $1 \beta$ levels in LPStreated RAW macrophages. The confocal images in Figure 5 show a significant reduction of IL-1 $\beta$ levels in NP22-treated macrophages (i.e., loss of red fluorescence), in a similar manner to TNF- $a$ (Figure S8), confirming the efficacy of the NPs against pro-inflammatory cytokines. 
To ascertain the toxicity of the optimal Col-IV IL-10 NP formulation (NP22) prior to atherosclerosis studies, an in vitro CCK-8 cell viability experiment with RAW 264.7 macrophages was carried out (Figure 6a). The results showed that cell viability was not discernibly affected by either the IL-10-containing or empty NPs, confirming that there is minimal difference between the toxicity of these two NPs. Next we investigated body and organ weight in C57BL/6J female mice treated for 14 days with 3 doses of empty NPs, free IL-10, or NP22 (Figure 6b and Table S1, respectively) and found that weights were similar and stable in all of the cohorts, and we observed no adverse effects. We next performed a single-dose toxicity study in healthy C57BL/6 mice to evaluate the effect of Col-IV IL-10 NP22 and control rIL-10 on clinical chemistry (Table S2), hematological (Table S3), and cytokine blood profiles (Table S4) as well as histopathology in the liver, spleen, kidney, and lung after single intravenous (i.v.) administration of Col-IV IL-10 NP22 to C57BL/6 mice (Figures S9 and S10), a low fluorescence signal was observed in the sectioned lung tissues (from the Alexa647 label in the NPs, Figure S9). Furthermore, the NPs did not cause any signs of toxicity based on clinical observations (observations included, but were not limited to, changes in the skin, fur, eyes, mucous membranes, respiratory system, circulatory system, autonomic central nervous system, somatomotor activity, locomotor activity, and behavioral pattern). The histological analysis did not reveal systemic toxicity, and microscopic analyses of histopathology of the liver, spleen, kidney, lung, and heart were all found to be within normal limits (Figure S10). The NPs had no impact on the blood levels of the pro-inflammatory cytokines interferon- $\gamma$, interleukin- 6 , and tumor necrosis factor- $a$, and none of these cytokines reached plasma levels exceeding the lower limit of quantification except for day 2 IL-6 levels in plasma from male mice dosed with rIL-10 control (Table S4). In view of these data, we chose a dose of $5 \mu \mathrm{g} /$ mouse IL-10 for the atherosclerosis and pharmacokinetic (PK) studies.

We next performed PK studies of Col-IV IL-10 NP22 and rIL-10 control in healthy C57BL/6 mice following a single i.v. injection. Blood samples were collected prior to NP administration at 6 time points between 2 and $24 \mathrm{~h}$ post-injection. No adverse clinical signs were observed prior to or following dosing (see above). Following a single i.v. administration of IL-10, peak plasma concentration, $C_{\max }$, and time to reach peak concentration $T_{\max }$ were measured before injection $(0 \mathrm{~h})$ and at 2 and $6 \mathrm{~h}$ post-injection (Table S5 and Figure S11). Peak plasma concentration, $C_{\max }$, and $T_{\max }$ were observed at $2 \mathrm{~h}$ post-dose. For both Col-IV IL-10 NP 22 and free rIL-10, the plasma concentrations declined to a level below the detection limit at $6 \mathrm{~h}$ post-dose.

To determine whether NP22 tempered acute inflammation in vivo, we conducted a preliminary experiment in which we used a model of self-limited peritonitis. ${ }^{53,54}$ This selflimited model of acute inflammation is driven by a peritoneal injection of zymosan A ( 0.2 $\mathrm{mg} / \mathrm{mouse}$ ). ${ }^{16}$ For these studies, C57BL/6J mice were also treated with vehicle (saline), NP22, or empty Col-IV NP at 100 or $500 \mathrm{ng} /$ mouse of IL-10 in NPs or $500 \mathrm{ng} / \mathrm{mouse}$ recombinant IL-10. Equal polymer concentrations were used in both the empty NPs and IL-10 NPs. The NP22 containing the higher dose of IL-10 significantly tempered zymosanstimulated polymorphonuclear neutrophils (PMNs) (Figure 7). Empty NPs did not exert a protective effect, indicating that the anti-inflammatory effect was due to the IL-10 and not the polymeric composition of the NPs. 
Furthermore, and consistent with the literature, ${ }^{55}$ there were few peritoneal macrophages at this time point (Figure S12), suggesting that the decrease in PMN may be due to tempering of the inflammatory response rather than to the clearance process, which predominantly occurs at later time points. ${ }^{55}$ This concept is consistent with the literature showing that IL-10 and its downstream signaling molecule (STAT3) down-regulate adhesion molecules and chemokines and thereby dampen leukocyte trafficking. ${ }^{56,57}$ Importantly, circulating PMNs and monocytes were not significantly different between rIL-10 control and Col-IV IL-10 NP22-treated groups (Figure S13 and Table S3).

Human atherosclerotic clinical syndromes occur when established, asymptomatic lesions progress to necrotic, "vulnerable-type" plaques. ${ }^{8}$ Moreover, because atherosclerosis begins later in the second decade of life in most cases, treatment typically begins in patients after atherosclerosis is already established. ${ }^{2}$ For these reasons, we proposed to investigate a NP treatment that began after atherosclerosis was established and continued through the period during which relatively stable lesions progress to necrotic plaques. In advanced atherosclerosis, macrophage apoptosis coupled with defective efferocytosis leads to postapoptotic macrophage necrosis, which contributes to plaque necrosis. ${ }^{4}$ Plaque necrosis destabilizes the plaque by amplifying lesional inflammation and by promoting fibrous cap thinning and rupture or erosion of the plaque, which then can trigger acute, occlusive lumenal thrombosis and tissue infarction. ${ }^{58}$ Therefore, therapeutic interventions that stabilize the plaque, thicken the cap, and reduce necrotic core size can be effective in the treatment of advanced atherosclerotic plaques. ${ }^{2}$ To test whether Col-IV IL-10 NPs (NP22) were protective against advanced atherosclerosis and could reduce plaque cap thinning, Ldlr ${ }^{-1-}$ mice were fed a Western-type high-fat/high-cholesterol diet for 12 weeks, after which Col-IV IL-10 NP22, free IL-10, control empty Col-IV NPs, or vehicle (Veh) control (normal saline) were injected i.v. once per week over a 4-week period. Body weights and plasma cholesterol were similar among the four groups of mice (Figure S14a-b). At the end of the study, aortic root lesions were harvested, and their cross sections were analyzed for hallmarks of advanced plaque progression that are associated with vulnerable plaques in humans, including thin fibrous caps and necrosis. ${ }^{8}$ First, confocal microscopy of these sections confirmed the presence of Alexa 647 fluorescence from Col-IV IL-10 NPs in the subendothelial regions of the plaques (Figure 8a). To further confirm that the NPs entered the lesions and were functional, we assessed p-STAT3 in lesions and found that the NP22treated group had increased p-STAT3 compared with empty control NPs (Ctrl NP) (Figure $\mathrm{S} 15)$. We also investigated sectioned liver and spleen tissue after the 5-week treatment, and low levels of fluorescence from the Col-IV IL-10 NPs were observed (Figure S16). The fluorescence signal intensity from these tissues was higher compared to the one-week single-dose toxicity study (Figure S9), and this could be due to increased accumulation of NPs after the 5-week treatment. Further experiments are required to elucidate long-term clearance of the NPs from these organs. Next, as expected for 16-week WD-fed $\mathrm{Ldlr}^{-1-}$ mice, the aortic root lesions of the Veh, empty Col-IV NP, and free IL-10 cohorts had relatively thin layers of subendothelial collagen (Figure 8b). In contrast, this collagen layer was significantly thicker in the group treated with Col-IV IL-10 NPs (NP22) compared with the other three groups (Figure 8c). Most importantly, NP22 vs vehicle control or empty NPs diminished necrotic core area in the lesions of these mice (Figure 9a-c). Col-IV IL-10 NP22 
also significantly decreased lesion oxidative stress compared with control NPs (Figures 9d and S17). Note that Col-IV IL-10 NP22 did not affect lesional macrophage or smooth muscle cell content (Figure S18), indicating that its protective effects were not being mediated by decreasing these inflammatory cells in lesions. Furthermore, defective clearance of apoptotic cells (efferocytosis) in advanced plaques promotes plaque necrosis, and in other settings, IL-10 has been associated with enhance efferocytosis. ${ }^{4}$ By quantifying macrophage-associated apoptotic cells vs free apoptotic cells in lesions as a measure of efferocytosis, ${ }^{48}$ we found that Col-IV IL-10 NP22 showed a trend $(P=0.05)$ toward enhanced lesional efferocytosis (Figure S19). These combined data show that atherosclerotic lesion-targeted NPs containing IL-10 have the capacity to stabilize, repair, and remodel preexisting advanced atherosclerotic plaques, which are key features of the resolution of inflammation.

\section{CONCLUSION}

Biologics such as recombinant proteins and peptides have recently attracted significant interest for the treatment of a range of conditions including cancer and inflammatory diseases. ${ }^{59,60}$ However, because these biologic therapeutics are mostly injected systemically, they suffer from rapid clearance from plasma and therefore require frequently repeat administration to achieve efficacy in chronic conditions like atherosclerosis. Furthermore, biologics including resolution mediators are not specific to the site of inflammation and may cause unwanted systemic side effects. ${ }^{61}$ In this context, NP-mediated delivery of biologics, including resolution mediators, can facilitate their targeted delivery, controlled release (allowing dose tempering), and protection from plasma components until released at the target site. ${ }^{58}$ Here we demonstrate the successful development, characterization, and in vivo delivery of the proresolving mediator IL-10 to atherosclerotic plaques and showed that this strategy can improve fibrous cap thickness and decrease necrotic core area after 4 weeks of weekly injections in mice with existing atherosclerosis. This work is an encouraging step toward the clinical translation of targeted proresolving nanotherapeutics that could become alternatives to conventional systemic anti-inflammatory therapies for the treatment of patients with high-risk cardiovascular diseases.

\section{METHODS}

Materials

See Supporting Information for full list of materials used.

\section{Formulation and Characterization of Col-IV IL-10 NPs}

All required polymers were either purchased or synthesized as previously described. ${ }^{16}$ For each NP, one polymer from core polymers 1 and one polymer from core polymers 2 (1:1 $\mathrm{wt} / \mathrm{wt}$ ratio), and PLGA-PEG-Col IV (5 wt/wt \% of total polymer mass) were predissolved in DMF (1 mL), vortexed, and sonicated for optimal mixing, and filtered through $0.2 \mu \mathrm{m}$ regenerated cellulose (RC) syringe filters (Sartorius, USA), with total polymer concentration $1.8 \mathrm{mg} / \mathrm{mL}$. Recombinant mouse IL-10 (R\&D Systems, cat no: $417 \mathrm{ML}$ ) and D-(+)glucosamine (4 and $6 \mathrm{wt} / \mathrm{wt} \%$ of total polymer mass, in $1 \mathrm{~mL}$ ultrapure DNase/RNase-free 
distilled water, total NP weight; $1.9 \mathrm{mg}$ ) were also mixed together by gentle pipetting and filtered through $0.2 \mu \mathrm{m}$ RC syringe filters. For in vivo experiments, PLGA-Alexa647 was synthesized as previously described ( $5 \mathrm{wt} / \mathrm{wt} \%$ of total polymer mass) and used for histological analysis. ${ }^{16}$ The organic phase was then split in two $(2 \times 0.5 \mathrm{~mL})$, and the three separate solutions ( 2 organic, 1 aqueous phase) were drawn up in glass Hamilton syringes and put through a glass microfluidic rapid-mixing chip with 3 inlets and 1 outlet for NP collection (see Figure S2), with the DMF solvent phase (containing the polymer blends) placed at either side of the middle channel, which contained the nonsolvent water phase carrying IL-10 and D-(+)-glucosamine (flow rate: $0.1 \mathrm{~mL} / \mathrm{min}$ for IL-10 solution and 0.05 $\mathrm{mL} / \mathrm{min}$ for polymer solutions). After termination of flow (10 min), the NPs were collected and concentrated by centrifugation at $3000 \mathrm{~g}$ for $20 \mathrm{~min}$ using Amicon Ultra-15 centrifugal filter units (MWCO $100 \mathrm{kDa}$, Sigma-Aldrich), washed with deionized water three times, and resuspended in $1 \mathrm{~mL}$ of either nuclease-free $\mathrm{H}_{2} \mathrm{O}$ or PBS and stored at $-80^{\circ} \mathrm{C}$ until use. After initial filtration and subsequent washes, all filtrates were collected, evaporated, and reduced, and IL-10 quantitated using the mouse DuoSet IL-10 ELISA kit and protocol (R\&D Systems, cat no: DY417-05). The NPs were then diluted 20-fold in either $\mathrm{H}_{2} \mathrm{O}$ or PBS, and their size and surface charge measured using DLS. For TEM, a $10 \mu \mathrm{L}$ solution of 1 $\mathrm{mg} / \mathrm{mL}$ freshly prepared NPs in $\mathrm{H}_{2} \mathrm{O}$ was deposited on 200-mesh Formvar/carbon-coated copper grids, the excess solution was blotted, and the grids were immersed in a solution of $0.75 \%$ uranyl formate stain, dried, and then imaged. The stain was blotted, and the dried grids imaged within $1 \mathrm{~h}$ of preparation on a Tecnai $\mathrm{G}^{2}$ Spirit BioTWIN electron microscope equipped with an AMT 2k CCD camera and low-dose software ( $80 \mathrm{kV}$, direct mag. 98000x).

\section{Western Blot Analysis of RAW 264.7 Macrophages}

For assessment of Col-IV IL-10 NP bioactivity, RAW 264.7 cells $\left(5 \times 10^{5}\right.$ cells/well) were seeded in 6-well plates and cultured in Dulbecco's modified eagle medium (DMEM, ATCC) supplemented with $10 \%$ heat-inactivated fetal bovine serum (FBS, Gibco) in a cell culture incubator $\left(37{ }^{\circ} \mathrm{C}\right.$ and $\left.5 \% \mathrm{CO}_{2}\right)$. After $24 \mathrm{~h}$, the cells were then treated with either the $24 \mathrm{Col}-$ IV IL-10 NPs, free recombinant IL-10 $(20 \mathrm{ng} / \mathrm{mL})$, or left untreated (cells only). The cells were then rinsed with ice-cold PBS $(3 \times 3 \mathrm{~mL})$ and harvested by scraping and transferring into Eppendorf tubes, followed by centrifugation at $12,000 \mathrm{rpm}$ for $5 \mathrm{~min}$ at $4{ }^{\circ} \mathrm{C}$. For protein extraction, the cells were lysed in $200 \mu \mathrm{L}$ of protein extraction reagent (Fisher Scientific, Pittsburgh, PA, USA) supplemented with protease inhibitor cocktail and phosphatase inhibitor cocktail (Sigma-Aldrich), and then centrifuged at 12,000 rpm for 10 $\min$ at $4{ }^{\circ} \mathrm{C}$ to remove the nuclei. Next, protein concentration was measured using a Coomassie Plus-Bradford assay with bovine serum albumin as the protein standard. The cell lysates (with $30 \mu \mathrm{g}$ of protein) were mixed with $4 \times$ Laemmli sample buffer (Bio-Rad), and the mixture was boiled for $7 \mathrm{~min}$ at $95{ }^{\circ} \mathrm{C}$. The proteins were separated by SDS-PAGE using Novex 4-12\% tris-glycine mini gels and subsequently electro-transferred onto an Immobilon-P polyvinylidene difluoride (PVDF) membrane (Millipore). Then the membranes were blocked with tri-sec-buffered saline $0.1 \%$ Tween 20 (TBST) solution containing $1 \% \mathrm{BSA}$ for $2 \mathrm{~h}$ at $4{ }^{\circ} \mathrm{C}$ on a shaker. The primary antibodies (1:1000 dilutions) in TBST with $1 \%$ BSA were incubated with the membranes overnight at $4{ }^{\circ} \mathrm{C}$ on a shaker. After that, the membranes were washed with TBST solution four times (each $10 \mathrm{~min}$ ) and then incubated with secondary antibody (1:5000 dilution) in TBST with $1 \%$ BSA for $1 \mathrm{~h}$ at 
room temperature on a shaker. Finally, the membranes were washed with TBST solution five times and visualized using Amersham ECL prime Western blotting detection reagent (GE Healthcare Life Sciences, Pittsburgh, PA, USA). The primary and secondary antibodies used in this study were from Cell Signaling Technology (Danvers, MA, USA) as follows: $\beta$-Actin (8H10D10) mouse mAb, phospho-Stat3 (Tyr705) (3E2) mouse mAb as the primary antibody, and antimouse IgG (HRP-linked) antibody as a secondary antibody.

\section{Analysis of ROS in RAW 264.7 Macrophages Treated With Col-IV IL-10 NPs}

To analyze the inhibitory effect of IL-10 on intracellular ROS in LPS-stimulated macrophages, RAW 264.7 cells were seeded on a 24 -well tissue culture plate $\left(2 \times 10^{4}\right.$ cells per well) and allowed to grow for $12 \mathrm{~h}$ in DMEM-supplemented medium with $10 \%$ heatinactivated FBS in a cell culture incubator $\left(37^{\circ} \mathrm{C}\right.$ and $\left.5 \% \mathrm{CO}_{2}\right)$. Next the cells were pretreated with LPS $(100 \mathrm{ng} / \mathrm{mL})$ for a further $24 \mathrm{~h}$ at $37^{\circ} \mathrm{C}$. The medium was then removed and replaced with medium containing Col-IV IL-10 NPs or recombinant IL-10 (50 ng/mL), followed by an additional $24 \mathrm{~h}$ incubation. Cells treated with no LPS or with LPS without NPs were included as controls. The cells were then washed with PBS and incubated with 10 $\mu \mathrm{M}$ ROS detection reagent $\left(\mathrm{H}_{2} \mathrm{DCFDA}\right)$ for $90 \mathrm{~min}$ at $37^{\circ} \mathrm{C}$. Fluorescence intensity was measured using a Synergy HT multimode microplate reader with ex/em 485/528 nm filter (BioTek Instruments Inc.).

\section{IL-10 Release Kinetics Experiment}

To analyze the release profiles of Col-IV IL-10 NPs, the protein-loaded NPs were dispersed in $1 \mathrm{~mL}$ of PBS and incubated in a shaking incubator at $100 \mathrm{rpm}$ and $37{ }^{\circ} \mathrm{C}$. At each time point, the protein released from NPs was isolated using Amicon Ultra- 0.5 centrifugal filters (MWCO $50 \mathrm{kDa}$ ) at 12,000 rpm for $10 \mathrm{~min}$ at $4{ }^{\circ} \mathrm{C}$. The Col-IV IL-10 NPs were resuspended in PBS and incubated in the same manner until the last defined time point. The amount of released protein at each time point was measured at $450 \mathrm{~nm}$ using the mouse DuoSet IL-10 ELISA kit and protocol (R\&D Systems, cat no: DY417-05). The measurements were done in triplicate.

\section{Quantitative Real-Time PCR (qPCR)}

Macrophage cells were seeded on a 6-well tissue culture plate $\left(5 \times 10^{5}\right.$ cells/well $)$ and maintained for $12 \mathrm{~h}$. The cells were treated with LPS $(500 \mathrm{ng} / \mathrm{mL})$ for $4 \mathrm{~h}$, the medium was replaced with free recombinant IL-10 or Col-IV IL-10 NPs (20 ng/mL of IL-10 was used), and the cells were incubated for $24 \mathrm{~h}$ at $37^{\circ} \mathrm{C}$. Next, the cells were washed with PBS and harvested by scraping, followed by centrifugation at $2000 \mathrm{rpm}$ for $5 \mathrm{~min}$ at $4{ }^{\circ} \mathrm{C}$. The isolated cell pellets were used to prepare the total RNA using the RNeasy Mini Kit (QIAGEN, Valencia, CA, USA) according to the manufacturer's protocol. For the preparation of cDNA, the extracted RNA solution $(1 \mu \mathrm{g} / 5 \mu \mathrm{L})$ was then mixed with $0.5 \mu \mathrm{L}$ of Oligo (dT) 15 primer (Promega, Madison, WI, USA) and then reacted at $70{ }^{\circ} \mathrm{C}$ for $5 \mathrm{~min}$ using the Bio-Rad iCycler PCR Thermal Cycler (Bio-Rad Laboratories, Inc., Hercules, CA, USA). The mixture was subsequently placed on ice for $5 \mathrm{~min}$ and mixed with various components to a final volume of $20 \mu \mathrm{L}$ : nuclease-free water $(5.6 \mu \mathrm{L}), 10 \mathrm{mM}$ dNTP mixture (Promega, $1 \mu \mathrm{L}$ ), $25 \mathrm{mM} \mathrm{MgCl}$ (Promega, $2.4 \mu \mathrm{L}$ ), ImProm-II reverse transcriptase (Promega, $1 \mu \mathrm{L}$ ), ImProm-II 5X reaction buffer (Promega, $4 \mu \mathrm{L}$ ), and RNasin Plus RNase 
inhibitor (Promega, $0.5 \mu \mathrm{L}$ ). Next, the mixture was subjected to Bio-Rad iCycler PCR Thermal Cycler in three steps: $5 \mathrm{~min}$ at $25^{\circ} \mathrm{C}, 60 \mathrm{~min}$ at $42^{\circ} \mathrm{C}$, and $15 \mathrm{~min}$ at $70{ }^{\circ} \mathrm{C}$. To analyze the gene expression of proinflammatory cytokines affected by IL-10 in LPSstimulated macrophage cells, the synthesized cDNA was mixed with the Rotor-Gene SYBR Green PCR Kit (QIAGEN) as a fluorescent reporter and then the primer mixture containing Tnfa (5' ${ }^{\prime}$-CCACCACGCTCTTCTGTCTA-3' and 5' ${ }^{\prime}$ AGGGTCTGGGCCATAGAACT-3') or $A c t b$ ( $\beta$-Actin) (5'-CGGTTCCGATGCCCTGAGGCTCTT-3' and $5^{\prime}$ CGTCACACTTCATGATGGAATTGA-3') primer pairs, respectively. Next, the final reaction mixture was subjected to qPCR cycling (Rotor-Gene Q, QIAGEN), and the amplification reactions were carried out using the following protocol. After an initial denaturation at $95{ }^{\circ} \mathrm{C}$ for $5 \mathrm{~min}$, the cycles processed to denaturation at $95{ }^{\circ} \mathrm{C}$ for $10 \mathrm{~s}$ and annealing and elongation at $60{ }^{\circ} \mathrm{C}$ for $20 \mathrm{~s}$ were performed 40 times. The relative gene expression levels were calculated using the $\Delta \Delta \mathrm{Ct}$ method and normalized to the expression of the reference gene, $A c t b$. The threshold cycle $(\mathrm{Ct})$ values of the target genes were also normalized to the values of unstimulated cells (control group). The measurements were carried out in triplicate.

\section{Mitochondrial ROS Measurement}

Mitochondrial superoxide generation was measured as described previously by labeling macrophages with a mitochondria-targeted superoxide detection probe, MitoSOX. ${ }^{49}$ Briefly, after the indicated cell treatments, macrophages were incubated with $5 \mu \mathrm{M}$ MitoSOX at $37^{\circ} \mathrm{C}$ for $30 \mathrm{~min}$ followed by two washes with $1 \times \mathrm{PBS} \mathrm{pH}$ 7.4. The intensity of MitoSOX fluorescence was quantified by flow cytometry (BD Facs CantoII), and the data were analyzed using FlowJo.

\section{Efferocytosis Assay with Col-IV IL-10 NPs}

Human Jurkat T cells were labeled with $5 \mu \mathrm{g} / \mathrm{mL}$ Calcein Green-AM for 30 min at $37^{\circ} \mathrm{C}$ followed by three washes with $1 \times$ PBS. The Calcein-labeled Jurkat cells were induced to undergo apoptosis by exposing them to UV light $(254 \mathrm{~nm})$ for $10 \mathrm{~min}$ followed by incubation for $2 \mathrm{~h}$ at $37{ }^{\circ} \mathrm{C}$. Using this protocol, we routinely obtained cells that were $>80 \%$ Annexin- $\mathrm{V}$ positive. The fluorescently labeled apoptotic Jurkat cells were then cultured with macrophages at a ratio of 5:1 (apoptotic cells:macrophages) for $1 \mathrm{~h}$ at $37{ }^{\circ} \mathrm{C}$. After washing away the unengulfed apoptotic cells, the remaining cells were imaged under a fluorescence microscope to quantify the percent of macrophages that engulfed at least one apoptotic cell.

\section{Confocal Microscopy to Assess Immunofluorescence of IL-1 $\beta$ or TNF- $a$}

RAW 264.7 cells were cultured on the surface of cover glasses (12-well cell plate) at a seeding density of 100,000/well and maintained in DMEM supplemented with $10 \%$ heatinactivated fetal bovine serum (HIFBS) and $0.1 \%$ of penicillin-streptomycin-amphotericin B solution at $37{ }^{\circ} \mathrm{C}$ and $5 \% \mathrm{CO}_{2}$. Cells were treated with IL-10 (500 ng/mL), Col-IV NP, or Col-IV IL-10 NP (NP22) for $24 \mathrm{~h}$. The samples were then incubated with LPS (100 ng/mL) for $6 \mathrm{~h}$ and finally washed and fixed with paraformaldehyde at $4 \%$ in PBS. The fixed cells were blocked and permeabilized with a solution containing BSA 1\%, and Triton X100 $0.25 \%$ for $1 \mathrm{~h}$ at RT and then incubated overnight at $4{ }^{\circ} \mathrm{C}$ with rabbit anti-IL- $1 \beta$ or antiTNF- $a$ mAb (1:500), and mouse anti- $a$-tubulin mAb diluted (1:1000). The samples were 
washed three times with BSA $0.2 \%$ and Triton X100 0.025\% (washing solution) for 5 min each and then incubated with Alexa Fluor 555 goat antirabbit Ab and Alexa Fluor 488 goat antimouse $\mathrm{Ab}$ for $1 \mathrm{~h}$ at RT, both diluted (1:1000) in the washing solution. The samples were washed and mounted on microscope slides with Fluoromount-G containing 1:3000 Hoechst 33342 for nuclear staining and analyzed by confocal microscopy using a FluoView FV1000 (Olympus) microscope.

\section{CCK-8 in Vitro Cell Viability Assay}

$24 \mathrm{~h}$ before dosing, RAW 246.7 cells were seeded at a density of $2.5 \times 10^{3}$ cells/well in a 96-well plate and maintained in DMEM supplemented with $10 \%$ HIFBS at $37{ }^{\circ} \mathrm{C}$ and $5 \%$ $\mathrm{CO}_{2}$. Next the cells were treated with empty Col-IV IL-10 or Col-IV IL-10 NP22 at 2 $\mathrm{mg} / \mathrm{mL}$ total polymer, with IL-10 doses at: $0.08,0.16,0.31,0.63,1.25,2.50,5.0$, and 10.00 $\mu \mathrm{g} / \mathrm{mL}$ and incubated for a further $48 \mathrm{~h}$. The medium was then removed, and cell counting kit-8 (CCK-8) assay solution $(1: 10,10 \mu \mathrm{L})$ was added to each well. The cells were incubated for a further $4 \mathrm{~h}$ at $37{ }^{\circ} \mathrm{C}$ and $5 \% \mathrm{CO}_{2}$, and the absorbance from the wells was measured at $450 \mathrm{~nm}$ using a microplate reader.

\section{Initial Characterization of C57BL/6J Mice Treated with NPs}

Healthy female C57BL/6J mice (8-10 wks old, Jackson Laboratory) were administered a single injection ( via tail vein) of either carrier-free recombinant IL-10, empty Col-IV NP, Col-IV NP (NP22), or saline at three IL-10 equiv doses of 5, 20, and $50 \mu \mathrm{g} /$ mouse (total injection volume of $150 \mu \mathrm{L}$ ) with 5 mice per group. The mice were weighed every day for 14 days and monitored for any adverse effects throughout. Weights of the organs (liver, spleen, kidney, lung, and heart) were recorded after trimming of any adherent tissue(s). Paired organs were weighed together.

\section{Single-Dose Toxicity Study with C57BL/6 Mice Administered with rlL-10 Control or Col IV IL-10 NP22}

Healthy C57BL/6 mice (8-10 wks) were administered a single injection (via tail vein) of either carrier-free recombinant IL-10 (rIL-10), or Col-IV IL-10 NP22, at IL-10 dose of $5 \mu \mathrm{g} /$ mouse (total injection volume of $150 \mu \mathrm{L}$ ) with 6 mice per group. The effect of these samples on clinical chemistry, hematological, and cytokine blood profiles as well as histopathology in the liver, spleen, kidney, and lungs after the single i.v. administration was analyzed. Postadministration, the animals were observed daily for clinical signs of toxicity, and findings were recorded as they were observed. Clinical observations included, but were not limited to, changes in the skin, fur, eyes, mucous membranes, respiratory system, circulatory system, autonomic central nervous system, somatomotor activity, locomotor activity, and behavioral pattern. During the clinical observation, the animals were also observed for morbidity/mortality daily. For the clinical observations, the following parameters were observed: respiratory, motor activities, convulsions, reflexes, ocular signs, cardiovascular signs, salivation, piloerection, analgesia, muscle tone, gastrointestinal signs, skin, death, others including food/water consumption, soiling of coat, behavior (aggressive or passive), wounds, vocalization. If all is normal the score will be zero (0). Clinical pathology, tissue, and cytokine analysis sample collection: Blood samples (approximately $0.5 \mathrm{~mL}$ ) were collected terminally by cardiac puncture from male mice in each group. Clinical pathology 
(clinical chemistry and hematology) and histopathology samples were collected on day 7 after administration. For clinical chemistry samples the serum fraction of the blood was prepared from blood collected in tubes with no anticoagulant (and assessed as per parameters listed in Table S3). For hematological analysis: the blood was collected in tubes containing K2-EDTA and mixed on rocking platform until analyzed (and assessed as per factors listed in Table S4). The gross necropsy observations included examination of the external surface of the body, all orifices, and the cranial, thoracic, and abdominal cavities and their contents post-sacrifice after 7 days. For histopathology: the liver, spleen, kidney, lung, and heart from each animal were fixed in 10\% neutral-buffered formalin (NBF), sectioned and analyzed by H\&E staining. For fluorescence imaging, brain, heart, thymus, lung, kidneys, spleen, liver, and stomach were collected at 24 post-dose from three animals dosed with Col-IV IL-10 NP22 and from three animals dosed with rIL-10, fixed in 10\% buffered formalin, embedded in paraffin, sectioned, fixed, stained with DAPI, and analyzed using an EVOS microscope. For cytokine analysis: blood samples for cytokine analysis were collected from nine (9) male and nine (9) female mice in each group on days 2 and 7.

Samples were placed into serum collection tubes with no anticoagulant and stored on wet ice until centrifuged to produce serum samples. The serum samples were transferred into vials and tightly capped. Samples were stored frozen at $-80 \pm 12{ }^{\circ} \mathrm{C}$ until assessed for cytokine analysis. For each cytokine (TNF- $a$, IL-6, and IFN- $\gamma$ ), three samples/sex/time point were analyzed by using ELISA assays commercially available (R\&D Systems kits catalogs \# m6000b, m1000b, and mta00b, respectively).

\section{Pharmacokinetic Study with C57BL/6 Mice Administered with rlL-10 Control or Col IV IL-10 NP22}

Healthy C57BL/6 mice (8-10 wks) were administered a single injection (via tail vein) of either carrier-free recombinant IL-10 (rIL-10), or Col IV IL-10 NP22, at IL-10 dose of $5 \mu \mathrm{g} /$ mouse (total injection volume of $150 \mu \mathrm{L}$ ). Blood samples were collected from 3 animals per group at $0 \mathrm{~h} \pm 4 \mathrm{~min}, 2 \mathrm{~h} \pm 5 \mathrm{~min}, 6 \mathrm{~h} \pm 10 \mathrm{~min}, 8 \mathrm{~h} \pm 10 \mathrm{~min}, 12 \mathrm{~h} \pm 15 \mathrm{~min}$, and $24 \mathrm{~h} \pm 15$ min. Blood samples (approximately $0.5 \mathrm{~mL}$ ) were collected terminally by cardiac puncture for analysis of plasma concentrations of IL-10. Samples were collected in tubes containing lithium-heparin and stored on wet ice until centrifuged to produce plasma samples. The plasma was stored at $80^{\circ} \mathrm{C}$ until analysis. The processed plasma samples from all animals were analyzed for IL-10 concentration using the method qualified according to Quantikine Mouse IL-10 Immunoassay Kit M100B instructions. PK analysis of the plasma concentrations of samples was performed using a noncompartmental module of WinNonlin (Pharsight Corporation, Mountain View, CA). For pharmacokinetics analysis, mean values of each time point were used. Evaluation included the following PK parameters the parameters listed in Table S5). All tables and figures were generated using Microsoft Excel 2010.

\section{Murine Peritonitis Study with Col-IV IL-10 NPs}

Female C57BL/6J mice (8-10 wks old, Jackson Laboratory) were administered zymosan A $\left(0.2 \mathrm{mg} /\right.$ mouse) in $1 \mathrm{~mL}$ of sterile saline to induce peritonitis via i.p. injections. ${ }^{16,62}$ Mice were euthanized with an overdose of isofluorane $4 \mathrm{~h}$ after zymosan injection, and peritoneal exudates were collected by lavaging with $\mathrm{Ca}^{2+} / \mathrm{Mg}^{2+}$-free phosphate-buffered saline 
$\left(\mathrm{PBS}^{-/-}, 5 \mathrm{~mL}\right.$ ), and blood was collected by heart puncture. Blood monocytes and PMN were analyzed with an automated cell counter. Peritoneal leukocytes were counted using a hemocytometer, and PMNs were quantified using a FACSCanto flow cytometer after staining with FITC-conjugated rat antimouse Ly-6G (clone 1A8), rat antimouse F4/80 (clone $\mathrm{BM} 8$ ), or rat $\mathrm{IgG} 2 \mathrm{c}, \boldsymbol{x}$ isotype control. For counting PMNs after NP administration, zymosan $(0.2 \mathrm{mg} /$ mouse) was administered i.p., followed by i.v. injections of Veh, empty NPs, NPs containing IL-10 (100 or $500 \mathrm{ng} /$ mouse), or native IL-10 (500 ng/mouse). All procedures were conducted in accordance with protocols approved by the Columbia University Standing Committee on Animals guidelines for animal care.

\section{Atherosclerotic Lesion Analysis after Treatment with Col-IV IL-10 NP22}

Male $\mathrm{Ldll}^{-/-}$mice (8-10 weeks old) were purchased from Jackson Laboratory and placed on a Western-type diet (WD; TD.88137, Harlan Teklad) for 12 wks. With the mice continuing on the WD, they were injected intravenously weekly with $200 \mu \mathrm{L}$ of one of the following: Col-IV IL-10 NP22, empty Col-IV NPs ( $5 \mu \mathrm{g}$ of IL-10/injection and an equivalent polymer amount), free IL-10 (5 $\mu \mathrm{g}$ per injection), or sterile saline (vehicle control). All procedures were conducted in accordance with protocols approved by the Columbia University Standing Committee on Animals guidelines for animal care. For morphometric lesion analysis, sections were stained with Harris' hematoxylin and eosin (H\&E). Total lesion area was quantified as previously described. For plaque necrosis, boundary lines were drawn around regions that were free of $\mathrm{H} \& \mathrm{E}$ staining, and area measurements were obtained using image analysis software. A $10,000 \mu \mathrm{m}^{2}$ threshold was implemented to avoid counting regions not likely to represent substantial areas of necrosis. Collagen staining was performed using picrosirius red as per the manufacturer's instructions (PolySciences, Inc.). Since fibrous cap thickness can vary throughout lesions, these values were assessed by averaging the thickness of the cap in 3 separate regions of the lesions and then expressed as arbitrary ratio units (AU) of cap thickness:lesion area (STM). ${ }^{17}$ Dihydroethidium (DHE) was used to detect oxidative stress in frozen aortic root tissues section. Frozen sections (4 separate section per mouse) were incubated with DHE $(5 \mu \mathrm{M})$ for $20 \mathrm{~min}, 37^{\circ} \mathrm{C}$. After $20 \mathrm{~min}$, excess DHE was removed by washing sections with PBS $(2 \times)$. Sections were then counterstained with Hoechst, and images were captured on a fluoresence microscope and processed via ImageJ. ${ }^{17}$ Lesional efferocytosis performed on frozen aortic root sections was assessed by counting apoptotic (TUNEL-positive) nuclei (DAPI) that were associated with lesional macrophages or not ("free"). Macrophage-associated apoptotic cells followed the criteria of TUNEL-positive nuclei surrounded by or in contact with neighboring F4/80+ macrophages. Free apoptotic cells exhibited nuclear condensation, loss of antibody F4/80 reactivity, and were not in contact with neighboring macrophages. Twenty apoptotic cells were counted per mouse. The analysis was conducted by an observer who was blinded to the identity of the samples. ${ }^{49}$

\section{Statistical Analysis}

All results are presented as means \pm SEM. $P$ values were calculated using the Student's $t$ test or one-way ANOVA with post-hoc Tukey analysis for normally distributed data. For nonnormally distributed data, the Mann-Whitney rank sum test was used. 


\section{Supplementary Material}

Refer to Web version on PubMed Central for supplementary material.

\section{Acknowledgments}

This research was supported by the NHLBI Program of Excellence in Nanotechnology (PEN) contract HHSN268201000045C. O.F. acknowledges NIH support from grants HL127464, CA151884, and EB015419; and by the David Koch-Prostate Cancer Foundation Award in Nanotherapeutics. I.T. acknowledges NIH support from grants HL127464, HL075662 and HL107497. G.F. acknowledges support from NIH Pathway to Independence K99 grant HL119587. C.V. acknowledges support from the Center for the Development of Nanoscience and Nanotechnology (Grant FB0807) and the Postdoctoral Program of Becas-Chile/CON-ICYT. We thank the Neurobiology Department and the Neurobiology Imaging Facility at Harvard Medical School for confocal microscopy experiments. This facility is supported in part by the Neural Imaging Center as part of an NINDS P30 Core Center grant no. NS072030. The authors also thank George Kuriakose at Columbia University for technical support along with the confocal and specialized microscopy core at Columbia University's Irving Cancer Research Center (ICRC).

\section{References}

1. Kotas ME, Medzhitov R. Homeostasis, Inflammation, and Disease Susceptibility. Cell. 2015; 160:816-827. [PubMed: 25723161]

2. Tabas I, Glass CK. Anti-inflammatory Therapy in Chronic Disease: Challenges and Opportunities. Science. 2013; 339:166-172. [PubMed: 23307734]

3. Merched AJ, Ko K, Gotlinger KH, Serhan CN, Chan L. Atherosclerosis: Evidence for Impairment of Resolution of Vascular Inflammation Governed by Specific Lipid Mediators. FASEB J. 2008; 22:3595-3606. [PubMed: 18559988]

4. Moore KJ, Tabas I. Macrophages in the Pathogenesis of Atherosclerosis. Cell. 2011; 145:341-355. [PubMed: 21529710]

5. Libby P, Tabas I, Fredman G, Fisher EA. Inflammation and its Resolution as Determinants of Acute Coronary Syndromes. Circ Res. 2014; 114:1867-1879. [PubMed: 24902971]

6. Tabas I, Williams KJ, Boren J. Subendothelial Lipoprotein Retention as the Initiating Process in Atherosclerosis: Update and Therapeutic Implications. Circulation. 2007; 116:1832-1844. [PubMed: 17938300]

7. Otsuka F, Kramer MC, Woudstra P, Yahagi K, Ladich E, Finn AV, de Winter RJ, Kolodgie FD, Wight TN, Davis HR, Joner M, Virmani R. Natural Progression of Atherosclerosis from Pathologic Intimal Thickening to Late Fibroatheroma in Human Coronary Arteries: A Pathology Study. Atherosclerosis. 2015; 241:772. [PubMed: 26058741]

8. Virmani R, Burke AP, Farb A, Kolodgie FD. Pathology of the Unstable Plaque. Prog Cardiovasc Dis. 2002; 44:349-356. [PubMed: 12024333]

9. Giugliano RP, Sabatine MS. Are PCSK9 Inhibitors the Next Breakthrough in the Cardiovascular Field? J Am Coll Cardiol. 2015; 65:2638-2651. [PubMed: 26088304]

10. Viola J, Soehnlein O. Atherosclerosis - a Matter of Unresolved Inflammation. Semin Immunol. 2015; 27:184. [PubMed: 25865626]

11. Back M, Hansson GK. Anti-inflammatory Therapies for Atherosclerosis. Nat Rev Cardiol. 2015; 12:199-211. [PubMed: 25666404]

12. Buckley CD, Gilroy DW, Serhan CN. Proresolving Lipid Mediators and Mechanisms in the Resolution of Acute Inflammation. Immunity. 2014; 40:315-327. [PubMed: 24656045]

13. Perretti M, D'Acquisto F. Annexin A1 and Glucocorticoids as Effectors of the Resolution of Inflammation. Nat Rev Immunol. 2009; 9:62-70. [PubMed: 19104500]

14. Serhan CN, Brain SD, Buckley CD, Gilroy DW, Haslett C, O'Neill LA, Perretti M, Rossi AG, Wallace JL. Resolution of Inflammation: State of the Art, Definitions and Terms. FASEB J. 2007; 21:325-332. [PubMed: 17267386]

15. Mulder WJ, Jaffer FA, Fayad ZA, Nahrendorf M. Imaging and Nanomedicine in Inflammatory Atherosclerosis. Sci Transl Med. 2014; 6:239sr1. [PubMed: 24898749] 
16. Kamaly N, Fredman G, Subramanian M, Gadde S, Pesic A, Cheung L, Fayad ZA, Langer R, Tabas I, Farokhzad OC. Development and In Vivo Efficacy of Targeted Polymeric InflammationResolving Nanoparticles. Proc Natl Acad Sci U S A. 2013; 110:6506-6511. [PubMed: 23533277]

17. Fredman G, Kamaly N, Spolitu S, Milton J, Ghorpade D, Chiasson R, Kuriakose G, Perretti M, Farokhzad O, Tabas I. Targeted Nanoparticles Containing the Proresolving Peptide Ac2-26 Protect Against Advanced Atherosclerosis in Hypercholesterolemic Mice. Sci Transl Med. 2015; 7:275ra20.

18. Cooray SN, Gobbetti T, Montero-Melendez T, McArthur S, Thompson D, Clark AJ, Flower RJ, Perretti M. Ligand-Specific Conformational Change of the G-protein-Coupled Receptor ALX/ FPR2 Determines Proresolving Functional Responses. Proc Natl Acad Sci U S A. 2013; 110:18232-18237. [PubMed: 24108355]

19. Iyer SS, Cheng G. Role of Interleukin 10 Transcriptional Regulation in Inflammation and Autoimmune Disease. Crit Rev Immunol. 2012; 32:23-63. [PubMed: 22428854]

20. Moore KW, de Waal Malefyt R, Coffman RL, O'Garra A. Interleukin-10 and the Interleukin-10 Receptor. Annu Rev Immunol. 2001; 19:683-765. [PubMed: 11244051]

21. Liu Y, Li D, Chen J, Xie J, Bandyopadhyay S, Zhang D, Nemarkommula AR, Liu H, Mehta JL, Hermonat PL. Inhibition of Atherogenesis in LDLR Knockout Mice by Systemic Delivery of Adeno-Associated Virus Type 2-hIL-10. Atherosclerosis. 2006; 188:19-27. [PubMed: 16300768]

22. Pinderski Oslund LJ, Hedrick CC, Olvera T, Hagenbaugh A, Territo M, Berliner JA, Fyfe AI. Interleukin-10 Blocks Atherosclerotic Events In vitro and In vivo. Arterioscler, Thromb, Vasc Biol. 1999; 19:2847-2853. [PubMed: 10591660]

23. Cavusoglu E, Marmur JD, Hojjati MR, Chopra V, Butala M, Subnani R, Huda MS, Yanamadala S, Ruwende C, Eng C, Pinsky DJ. Plasma Interleukin-10 Levels and Adverse Outcomes in Acute Coronary Syndrome. Am J Med. 2011; 124:724-730. [PubMed: 21787901]

24. Huang Y, Li T, Sane DC, Li L. IRAK1 Serves as a novel regulator essential for lipopolysaccharideinduced interleukin-10 gene expression. J Biol Chem. 2004; 279:51697-51703. [PubMed: 15465816]

25. Hirata N, Yanagawa Y, Ogura H, Satoh M, Noguchi M, Matsumoto M, Togashi H, Onoe K, Iwabuchi K. The Role of Tumor Necrosis Factor-Alpha for Interleukin-10 Production by Murine Dendritic Cells. Cell Immunol. 2011; 266:165-171. [PubMed: 20979991]

26. Choi WI, Kamaly N, Riol-Blanco L, Lee IH, Wu J, Swami A, Vilos C, Yameen B, Yu M, Shi J, Tabas I, von Andrian UH, Jon S, Farokhzad OC. A Solvent-Free Thermosponge Nanoparticle Platform for Efficient Delivery of Labile Proteins. Nano Lett. 2014; 14:6449-6455. [PubMed: 25333768]

27. Tilg H, van Montfrans C, van den Ende A, Kaser A, van Deventer SJ, Schreiber S, Gregor M, Ludwiczek O, Rutgeerts P, Gasche C, Koningsberger JC, Abreu L, Kuhn I, Cohard M, LeBeaut A, Grint P, Weiss G. Treatment of Crohn's Disease with Recombinant Human Interleukin 10 Induces the Proinflammatory Cytokine Interferon Gamma. Gut. 2002; 50:191-195. [PubMed: 11788558]

28. Lauw FN, Pajkrt D, Hack CE, Kurimoto M, van Deventer SJ, van der Poll T. Proinflammatory Effects of IL-10 During Human Endotoxemia. J Immunol. 2000; 165:2783-2789. [PubMed: 10946310]

29. Almer G, Frascione D, Pali-Scholl I, Vonach C, Lukschal A, Stremnitzer C, Diesner SC, JensenJarolim E, Prassl R, Mangge H. Interleukin-10: an Anti-Inflammatory Marker to Target Atherosclerotic Lesions via PEGylated Liposomes. Mol Pharmaceutics. 2013; 10:175-186.

30. Almer G, Summers KL, Scheicher B, Kellner J, Stelzer I, Leitinger G, Gries A, Prassl R, Zimmer A, Mangge H. Interleukin 10-Coated Nanoparticle Systems Compared for Molecular Imaging of Atherosclerotic Lesions. Int J Nanomed. 2014; 9:4211-4222.

31. Kamaly N, Xiao Z, Valencia PM, Radovic-Moreno AF, Farokhzad OC. Targeted Polymeric Therapeutic Nanoparticles: Design, Development and Clinical Translation. Chem Soc Rev. 2012; 41:2971-3010. [PubMed: 22388185]

32. Shi J, Xiao Z, Kamaly N, Farokhzad OC. Self-Assembled Targeted Nanoparticles: Evolution of Technologies and Bench to Bedside Translation. Acc Chem Res. 2011; 44:1123-1134. [PubMed: 21692448] 
33. Langer R, Folkman J. Polymers for the Sustained Release of Proteins and other Macromolecules. Nature. 1976; 263:797-800. [PubMed: 995197]

34. Langer R. Polymer-Controlled Drug-Delivery Systems. Acc Chem Res. 1993; 26:537-542.

35. Bertrand N, Wu J, Xu X, Kamaly N, Farokhzad OC. Cancer Nanotechnology: the Impact of Passive and Active Targeting in the Era of Modern Cancer Biology. Adv Drug Delivery Rev. 2014; 66:2-25.

36. Lobatto ME, Fuster V, Fayad ZA, Mulder WJ. Perspectives and Opportunities for Nanomedicine in the Management of Atherosclerosis. Nat Rev Drug Discovery. 2011; 10:835-852. [PubMed: 22015921]

37. Chan JM, Zhang L, Tong R, Ghosh D, Gao W, Liao G, Yuet KP, Gray D, Rhee JW, Cheng J, Golomb G, Libby P, Langer R, Farokhzad OC. Spatiotemporal Controlled Delivery of Nanoparticles to Injured Vasculature. Proc Natl Acad Sci U S A. 2010; 107:2213-2218. [PubMed: 20133865]

38. Kalluri R. Basement Membranes: Structure, Assembly and Role in Tumour Angiogenesis. Nat Rev Cancer. 2003; 3:422-433. [PubMed: 12778132]

39. Chan JM, Rhee JW, Drum CL, Bronson RT, Golomb G, Langer R, Farokhzad OC. In Vivo Prevention of Arterial Restenosis with Paclitaxel-Encapsulated Targeted Lipid-Polymeric Nanoparticles. Proc Natl Acad Sci U S A. 2011; 108:19347-19352. [PubMed: 22087004]

40. Gu F, Zhang L, Teply BA, Mann N, Wang A, Radovic-Moreno AF, Langer R, Farokhzad OC. Precise Engineering of Targeted Nanoparticles by Using Self-Assembled Biointegrated Block Copolymers. Proc Natl Acad Sci U S A. 2008; 105:2586-2591. [PubMed: 18272481]

41. Quintanar-Guerrero D, Allemann E, Fessi H, Doelker E. Preparation Techniques and Mechanisms of Formation of Biodegradable Nanoparticles from Preformed Polymers. Drug Dev Ind Pharm. 1998; 24:1113-1128. [PubMed: 9876569]

42. Lim JM, Swami A, Gilson LM, Chopra S, Choi S, Wu J, Langer R, Karnik R, Farokhzad OC. Ultra-high Throughput Synthesis of Nanoparticles with Homogeneous Size Distribution Using a Coaxial Turbulent Jet Mixer. ACS Nano. 2014; 8:6056-6065. [PubMed: 24824296]

43. Valencia PM, Pridgen EM, Rhee M, Langer R, Farokhzad OC, Karnik R. Microfluidic Platform for Combinatorial Synthesis and Optimization of Targeted Nanoparticles for Cancer Therapy. ACS Nano. 2013; 7:10671-10680. [PubMed: 24215426]

44. Capiralla H, Vingtdeux V, Venkatesh J, Dreses-Werringloer U, Zhao H, Davies P, Marambaud P. Identification of Potent Small-Molecule Inhibitors of STAT3 with Anti-Inflammatory Properties in RAW 264.7 Macrophages. FEBS J. 2012; 279:3791-3799. [PubMed: 22909341]

45. Tedgui A, Mallat Z. Cytokines in Atherosclerosis: Pathogenic and Regulatory Pathways. Physiol Rev. 2006; 86:515-581. [PubMed: 16601268]

46. Fredenberg S, Wahlgren M, Reslow M, Axelsson A. The Mechanisms of Drug Release in poly(lactic-co-glycolic acid)-Based Drug Delivery Systems-a Review. Int J Pharm. 2011; 415:3452. [PubMed: 21640806]

47. Kang J, Lambert O, Ausborn M, Schwendeman SP. Stability of Proteins Encapsulated in Injectable and Biodegradable Poly(lactide-co-glycolide)-Glucose Millicylinders. Int J Pharm. 2008; 357:235-243. [PubMed: 18384984]

48. Thorp E, Cui D, Schrijvers DM, Kuriakose G, Tabas I. Mertk Receptor Mutation Reduces Efferocytosis Efficiency and Promotes Apoptotic Cell Accumulation and Plaque Necrosis in Atherosclerotic Lesions of Apoe-/- Mice. Arterioscler, Thromb, Vasc Biol. 2008; 28:1421-1428. [PubMed: 18451332]

49. Wang Y, Wang GZ, Rabinovitch PS, Tabas I. Macrophage Mitochondrial Oxidative Stress Promotes Atherosclerosis and Nuclear Factor-KappaB-Mediated Inflammation in Macrophages. Circ Res. 2014; 114:421-433. [PubMed: 24297735]

50. Tabas I. Consequences and Therapeutic Implications of Macrophage Apoptosis in Atherosclerosis: the Importance of Lesion Stage and Phagocytic Efficiency. Arterioscler, Thromb, Vasc Biol. 2005; 25:2255-2264. [PubMed: 16141399]

51. Tabas I. Macrophage Death and Defective Inflammation Resolution in Atherosclerosis. Nat Rev Immunol. 2010; 10:36-46. [PubMed: 19960040] 
52. Dinarello CA. A Clinical Perspective of IL-1beta as the Gatekeeper of Inflammation. Eur J Immunol. 2011; 41:1203-1217. [PubMed: 21523780]

53. Bannenberg GL, Chiang N, Ariel A, Arita M, Tjonahen E, Gotlinger KH, Hong S, Serhan CN. Molecular Circuits of Resolution: Formation and Actions of Resolvins and Protectins. J Immunol. 2005; 174:4345-4355. [PubMed: 15778399]

54. Schwab JM, Chiang N, Arita M, Serhan CN. Resolvin E1 and Protectin D1 Activate InflammationResolution Programmes. Nature. 2007; 447:869-874. [PubMed: 17568749]

55. Gautier EL, Ivanov S, Lesnik P, Randolph GJ. Local Apoptosis Mediates Clearance of Macrophages from Resolving Inflammation in Mice. Blood. 2013; 122:2714-2722. [PubMed: 23974197]

56. Matsukawa A, Kudo S, Maeda T, Numata K, Watanabe H, Takeda K, Akira S, Ito T. Stat3 in Resident Macrophages as a Repressor Protein of Inflammatory Response. J Immunol. 2005; 175:3354-3359. [PubMed: 16116228]

57. Scapini P, Laudanna C, Pinardi C, Allavena P, Mantovani A, Sozzani S, Cassatella MA. Neutrophils Produce Biologically Active Macrophage Inflammatory protein-3alpha(MIP-3alpha)/ CCL20 and MIP-3beta/CCL19. Eur J Immunol. 2001; 31:1981-1988. [PubMed: 11449350]

58. Soehnlein O. (Re)solving Atherosclerosis. Sci Transl Med. 2015; 7:275fs7.

59. Mitragotri S, Burke PA, Langer R. Overcoming the Challenges in Administering Biopharmaceuticals: Formulation and Delivery Strategies. Nat Rev Drug Discovery. 2014; 13:655672. [PubMed: 25103255]

60. Moghimi SM, Peer D, Langer R. Reshaping the Future of Nanopharmaceuticals. ACS Nano. 2011; 5:8454-8458. [PubMed: 21992178]

61. Fullerton JN, O'Brien AJ, Gilroy DW. Pathways Mediating Resolution of Inflammation: when Enough is too Much. Journal of Pathology. 2013; 231:8-20. [PubMed: 23794437]

62. Norling LV, Spite M, Yang R, Flower RJ, Perretti M, Serhan CN. Cutting edge: Humanized Nanoproresolving Medicines Mimic Inflammation-Resolution and Enhance Wound Healing. J Immunol. 2011; 186:5543-5547. [PubMed: 21460209] 
a

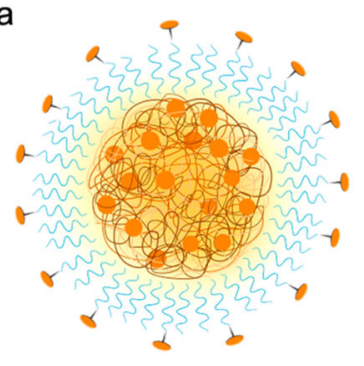

Col-IV IL-10 NP (NP 22)

$\sim \sim \mathrm{NH}_{2}$-PLGA-NH

$\sim \sim \sim$ PDLA-PEG-OMe

$\sim \sim \sim P L G A-P E G-C o l$ IV

- IL-10

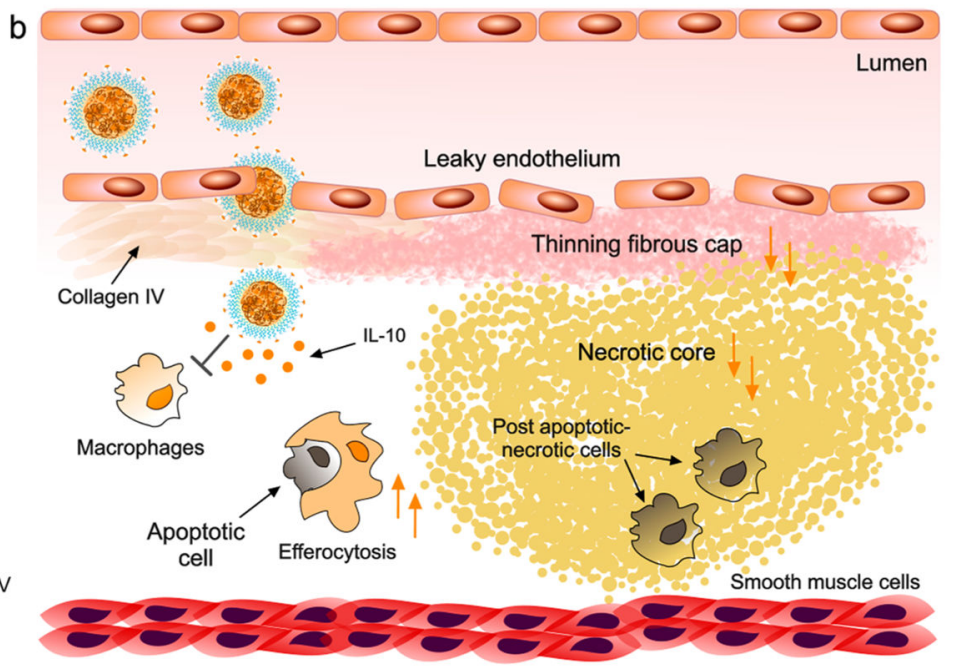

Figure 1.

Targeted anti-inflammatory NP design and application to resolution of inflammation in atherosclerotic plaques. (a) Col-IV IL-10 NP (NP22) identified from screening 24

formulations was fabricated by nanoprecipitation using a glass microfluidic rapid-mixing chip. The NPs were formed in a single self-assembly step and consisted of a blend of $\mathrm{NH}_{2}{ }^{-}$ PLGA-NH 2 , PDLA-PEG-OMe, PLGA-PEG-Col IV, and IL-10 in addition to D-(+)glucosamine hydrochloride as an IL-10-stabilizing additive and cryoprotectant. (b) The targeted NPs can enter plaques via leaky endothelial junctions and bind to exposed collagen IV (Col IV) and release their therapeutic inflammation-resolving IL-10 payload within the plaque over time, resulting in increased efferocytosis, an increase in cap size, and a decrease in necrotic core size (orange arrows). 


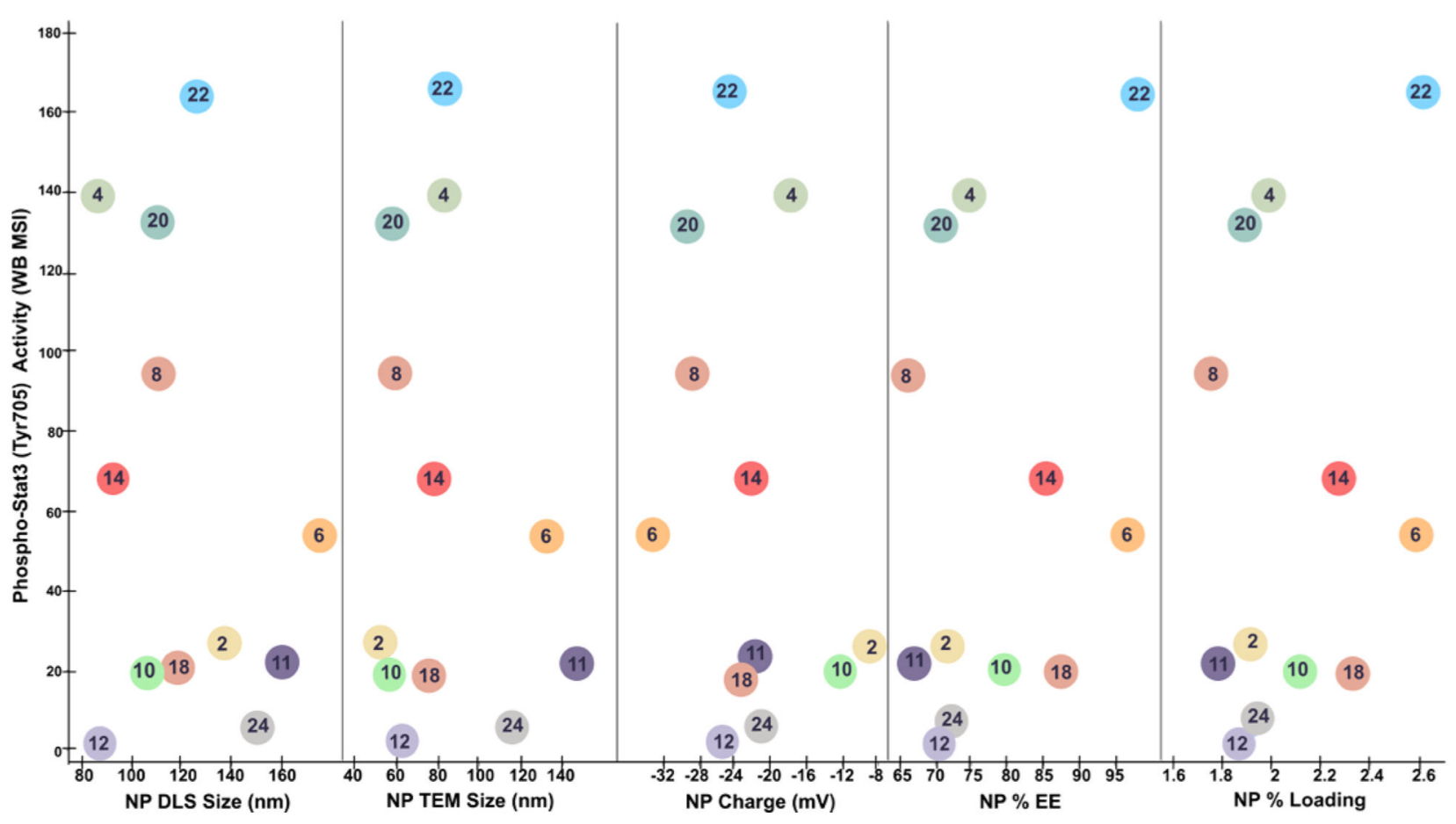

Figure 2.

Biophysicochemical properties of Col-IV IL-10 NPs. NP hydrodynamic size, measured using DLS measurements (mean $\pm \mathrm{SD}, n=3$ ), TEM actual size measurements (mean $\pm \mathrm{SD}$, $n=10), \zeta$ potential $(\mathrm{mV})($ mean $\pm \mathrm{SD}, n=6), \% \mathrm{EE}$, and $\%$ loading (IL-10 wt/wt $\%$ of total polymer mass), plotted together against the densitometric ratio of $\mathrm{p}$-STAT3: $\beta$-actin Western blot mean signal intensity measured in RAW 264.7 macrophages incubated with the indicated NPs (IL-10 dose: $500 \mathrm{ng} / \mathrm{mL}$ ) containing the amino-sugar D-(+)-glucosamine additive. 

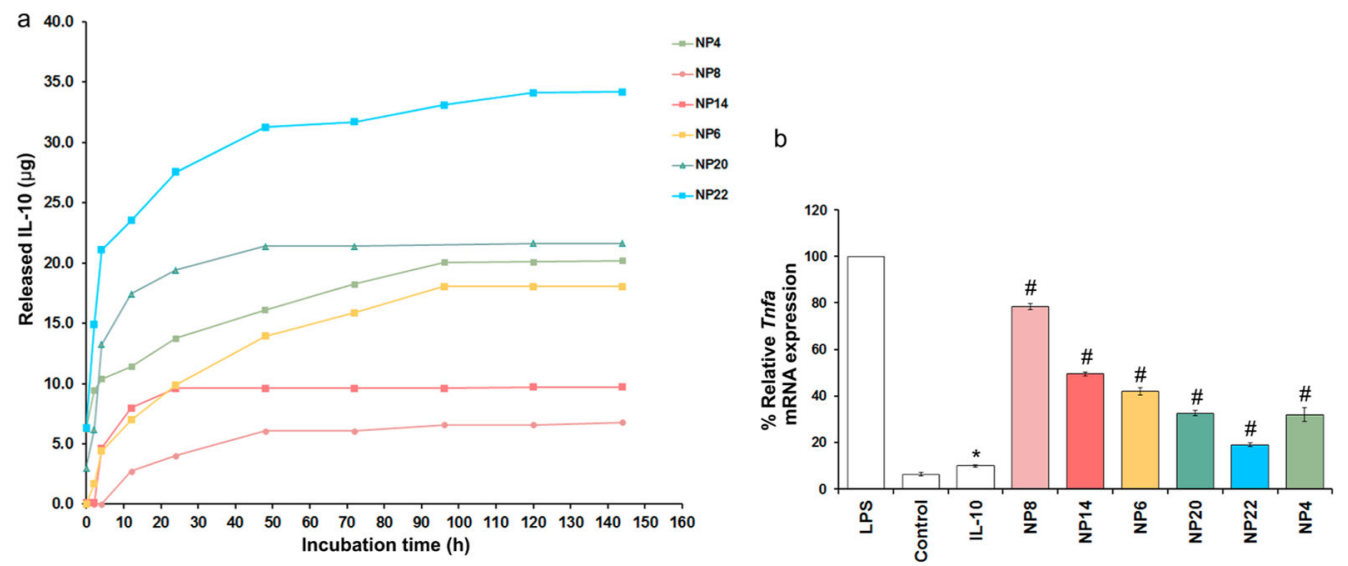

Figure 3.

Release kinetics Tnfa-suppressing activity of IL-10 from selected Col-IV IL-10 NPs. (a) In vitro cumulative release curve of Col-IV IL-10 NPs incubated at $37{ }^{\circ} \mathrm{C}$ in PBS (mean \pm SD, $n=3$ ). The released protein at different time points was isolated by filtration, and IL-10 ELISA was used to estimate the mass of protein released. (b) Relative expression of Tnfa mRNA after LPS treatment $(500 \mathrm{ng} / \mathrm{mL})$ for $4 \mathrm{~h}$, followed by treatment with free IL-10 or Col-IV IL-10 NPs $(20 \mathrm{ng} / \mathrm{mL})$ for $24 \mathrm{~h}$ at $37{ }^{\circ} \mathrm{C}(n=3) ; * p<0.05$ as compared with control; $\# p<0.05$ as compared with IL-10. 
a

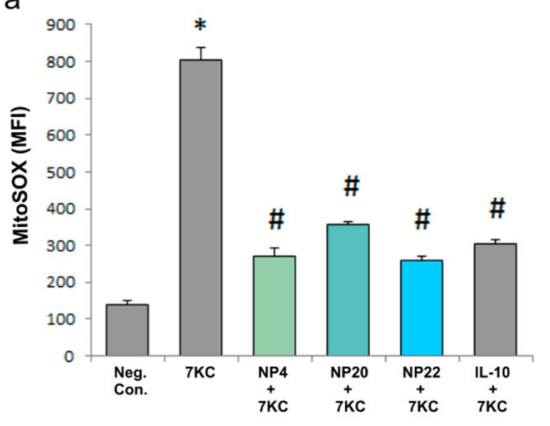

b

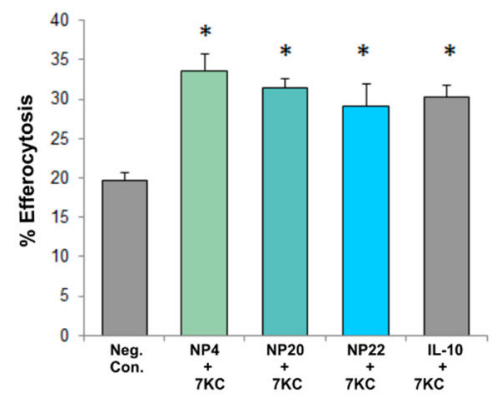

Figure 4.

Ex vivo investigation of Col-IV IL-10 NP's anti-inflammatory efficacy. (a) Bone marrowderived macrophages were preincubated with recombinant IL10 or IL10-NPs (NP22, NP20, and NP4) (IL-10 dose: $10 \mathrm{ng} / \mathrm{mL}$ ) for $12 \mathrm{~h}$, followed by treatment with 7-ketocholesterol (7KC) for $6 \mathrm{~h}$. The cells were stained with MitoSOX, a mitochondria-targeted ROS probe, followed by flow-cytometric analysis; ${ }^{*} p<0.05$ as compared with control; \# $p<0.05$ as compared with 7KC-treated group. (b) Bone marrow-derived macrophages were treated with IL10 or IL10-NPs (IL-10 dose: $10 \mathrm{ng} / \mathrm{mL}$ ) for $12 \mathrm{~h}$, following which fluorescently labeled apoptotic Jurkat cells were added at an apoptotic cell: macrophage ratio of 5:1 and cultured for $1 \mathrm{~h}$. Uptake of apoptotic cells by macrophages was analyzed by microscopy; ${ }^{*} p<0.05$. 


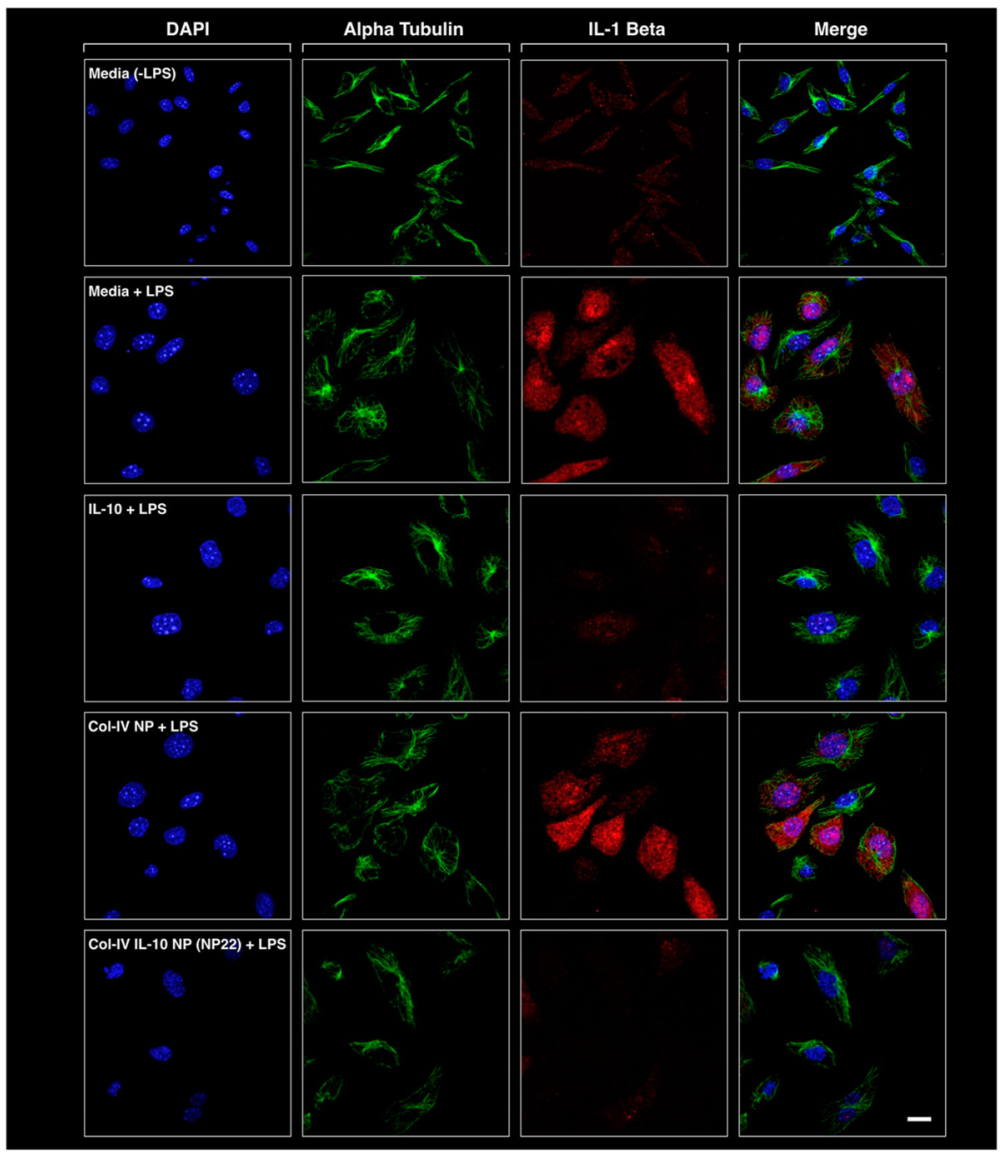

Figure 5.

Confocal microscopy of RAW 264.7 macrophages incubated with Col-IV IL-10 NP (NP22) and controls, and then stimulated with LPS. RAW 264.7 macrophages were incubated with IL-10 or NP22 (500 ng/mL IL-10) for $24 \mathrm{~h}$, followed by LPS stimulation (100 ng/mL) for 6 h. Blue: Hoechst, green: $a$-tubulin, red: IL-1 $\beta$, scale bar $=20 \mu \mathrm{m}$. 
a
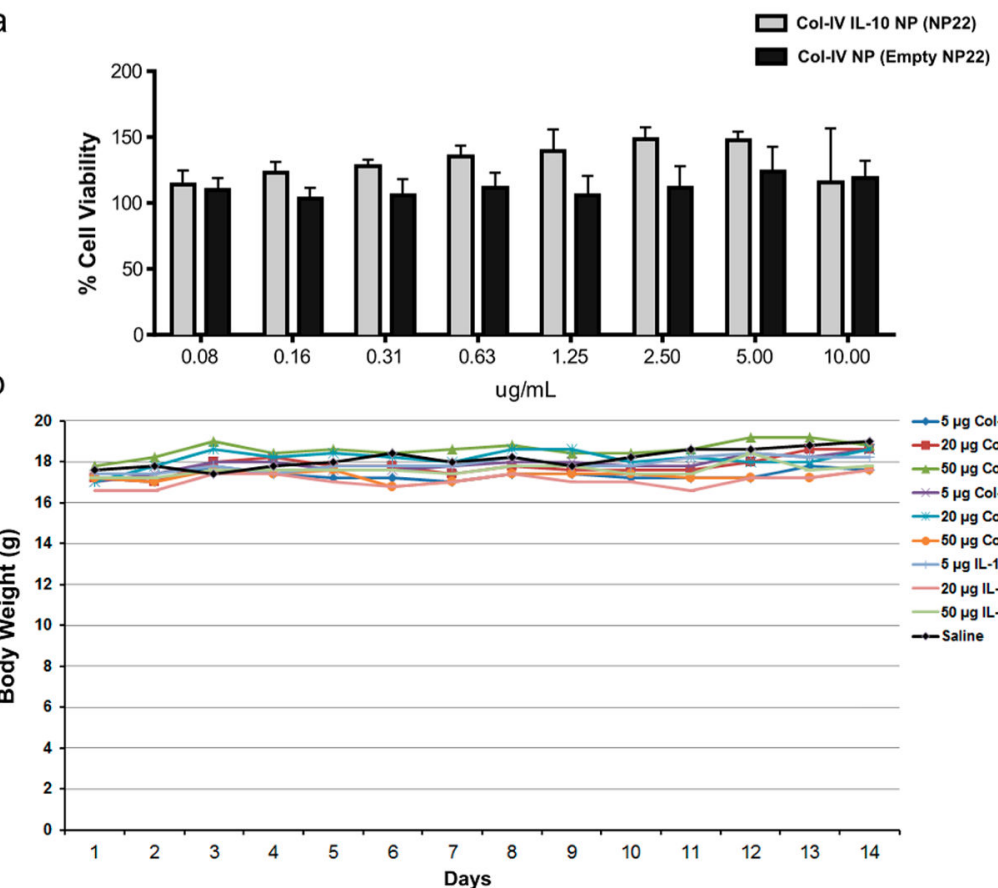

$\rightarrow-5 \mu \mathrm{g} \mathrm{Col-IV} \mathrm{IL-10} \mathrm{NP} \mathrm{(NP22)}$ $-20 \mu \mathrm{g} \mathrm{COl-HV} \mathrm{IL-10} \mathrm{NP} \mathrm{(NP22)}$ $-50 \mu \mathrm{g} \mathrm{ColtV} \mathrm{IL-10} \mathrm{NP} \mathrm{(NP22)}$ -5 ug Col-ly NP $-20 \mu \mathrm{g}$ Col-HV NP $-50 \mu \mathrm{g} \mathrm{Col-HV} \mathrm{NP}$ $-5 \mu \mathrm{g} \mathrm{IL}-10$

$20 \mu \mathrm{g}$ IL-10

$50 \mu \mathrm{g}$ IL-10

Figure 6.

In vitro and in vivo toxicity investigations of NP22. (a) RAW 264.7 macrophages were incubated with medium alone or medium containing Col-IV IL-10 NP (NP22) or empty ColIV NPs at various doses $(0.08-10 \mu \mathrm{g} / \mathrm{mL})$ for $48 \mathrm{~h}$, and cell viability assessed relative to medium alone using the tetrazolium salt-based cell-viability CCK- 8 assay (mean $\pm \mathrm{SD}, n=$ 6). (b) Evaluation of a range of IL-10 NP doses in healthy C57BL/6J mice. The different groups of mice received a single i.v. dose of 5, 20, or $50 \mu \mathrm{g}$ of free IL-10, Col-IV IL-10 (NP22), or equivalent empty Col-IV NP dose, and a control group received saline. The body weight and physical condition of all the mice was monitored for 14 days $(n=6)$. 


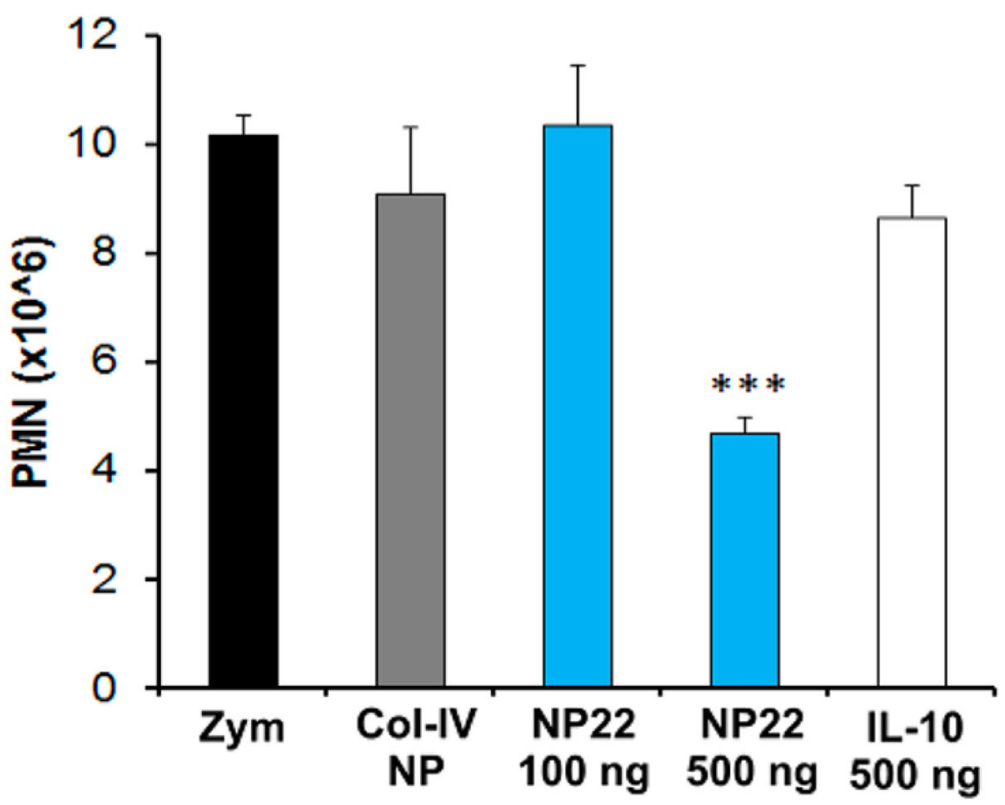

Figure 7.

NP22 limits neutrophil infiltration in vivo. Col-IV IL-10 NP22, empty NPs, free IL-10, or saline was administered by i.v. injection to C57BL/6J female mice. After $2 \mathrm{~h}$, zymosan (0.2 $\mathrm{mg} / \mathrm{mouse}$, Zym) was injected i.p., and peritoneal exudates were harvested $4 \mathrm{~h}$ later. Total live exudate cells were quantified using trypan blue exclusion, and polymorphonuclear neutrophils (PMNs) were assessed by flow cytometry ( $n=3$ mice/treatment; mean \pm SEM). $* * * p<0.001$ vs all other groups. 

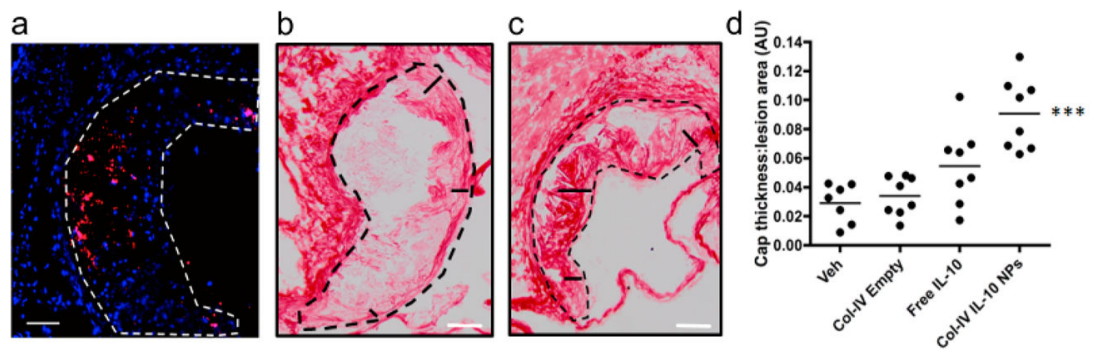

Figure 8.

Col IV-IL-10 NPs increase subendothelial collagen in $\mathrm{Ldlr}^{-/-}$mice with established atherosclerosis. $\mathrm{Ldlr}^{-1-}$ mice were fed the Western diet for $12 \mathrm{wks}$ and then injected i.v. with vehicle, free IL-10, or Col-IV NPs (empty) or Col-IV IL-10 NPs (NP22) once per week for 4 wks, with the mice remaining on the diet. (a) Images of $4^{\prime}, 6$-diamidino-2-phenylindole (DAPI)-stained aortic roots section showing NP22 (in pink) and nuclei (blue). The lesion is outlined by the white dotted box, white scale bar $=50 \mu \mathrm{m}$. Aortic root sections from the indicated groups of mice were stained with picrosirius red. The pair of images from the 16week Col IV NP (b) and Col-IV IL-10 NP (c) cohorts shows examples of lines used to measure cap thickness. (d) The microscopic images were quantified by image processing for fibrous cap thickness:lesion area ratio, expressed as arbitrary ratio units (AU). Data are mean \pm SEM ( $n=7-8$ separate mice, 2 sections/mouse); *** $P<0.001$ vs all other groups, oneway ANOVA with post-hoc Tukey analysis, white scale bar $=100 \mu \mathrm{m}$. 

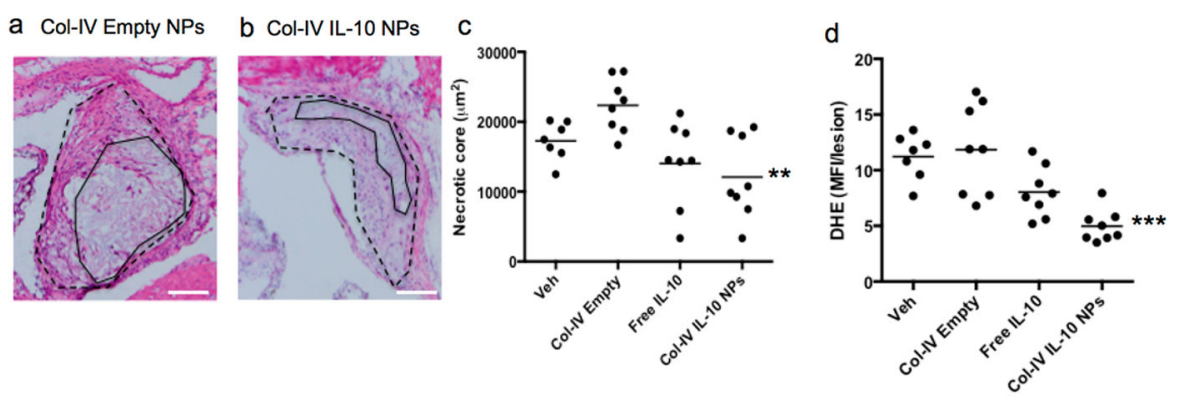

Figure 9.

Col IV-IL-10 NPs decrease necrosis in $\mathrm{Ldll}^{-/-}$mice with established atherosclerosis. $\mathrm{Ldlr}^{-/-}$ mice were fed the Western diet for $12 \mathrm{wks}$ and then injected i.v. with vehicle, free IL-10, or Col IV-NPs containing vehicle or IL-10 once per week for $4 \mathrm{wks}$, with the mice remaining on the WD. Aortic root sections from the indicated groups of mice were stained with H\&E. (a) Images from the 16-week Col-IV NPs (empty) and (b) Col-IV IL-10 NP cohorts shows examples of necrotic cores outlined in solid black lines. The microscopic images were quantified by image processing and expressed as $\mu \mathrm{m}^{2}$. Data are mean \pm SEM $(n=7-8$ separate mice, 2 sections/mouse); $* * P<0.01$, one-way ANOVA with post-hoc Tukey analysis, scale bar $=100 \mu \mathrm{m}$. (d) Aortic roots lesion sections were assessed for lesional superoxide using the DHE probe. Images were acquired on a fluorescence microscope and lesion DHE MFI was analyzed using ImageJ software. Data are mean \pm SEM $(n=7-8$ separate mice, 2 sections/mouse); $* * * P<0.001$, one-way ANOVA with post-hoc Tukey analysis. 